Article

\title{
Synthesis of New Imidazopyridine Nucleoside Derivatives Designed as Maribavir Analogues
}

\author{
Georgios Papadakis ${ }^{1}$, Maria Gerasi ${ }^{1}$, Robert Snoeck ${ }^{2}$, Panagiotis Marakos ${ }^{1}$, Graciela Andrei ${ }^{2}(\mathbb{D}$, \\ Nikolaos Lougiakis ${ }^{1, *}$ and Nicole Pouli ${ }^{1}$ \\ 1 Division of Pharmaceutical Chemistry, Department of Pharmacy, National and Kapodistrian University of \\ Athens, Panepistimiopolis-Zografou, 15771 Athens, Greece; gpapadakis@pharm.uoa.gr (G.P.); \\ mairager@pharm.uoa.gr (M.G.); marakos@pharm.uoa.gr (P.M.); pouli@pharm.uoa.gr (N.P.) \\ 2 Laboratory of Virology \& Chemotherapy, Rega Institute, KU Leuven, 3000 Leuven, Belgium; \\ robert.snoeck@kuleuven.be (R.S.); graciela.andrei@kuleuven.be (G.A.) \\ * Correspondence: nlougiak@pharm.uoa.gr
}

Academic Editor: Katherine Seley-Radtke

Received: 10 September 2020; Accepted: 29 September 2020; Published: 3 October 2020

\begin{abstract}
The strong inhibition of Human Cytomegalovirus (HCMV) replication by benzimidazole nucleosides, like Triciribine and Maribavir, has prompted us to expand the structure-activity relationships of the benzimidazole series, using as a central core the imidazo[4,5-b]pyridine scaffold. We have thus synthesized a number of novel amino substituted imidazopyridine nucleoside derivatives, which can be considered as 4-(or 7)-aza-D-isosters of Maribavir and have evaluated their potential antiviral activity. The target compounds were synthesized upon glycosylation of suitably substituted 2-aminoimidazopyridines, which were prepared in six steps starting from 2-amino-6-chloropyridine. Even if the new compounds possessed only a slight structural modification when compared to the original drug, they were not endowed with interesting antiviral activity. Even so, three derivatives showed promising cytotoxic potential.
\end{abstract}

Keywords: benzimidazole; nucleosides; imidazo[4,5-b]pyridine; HCMV; antiviral activity; antiproliferative activity

\section{Introduction}

Human cytomegalovirus (HCMV) is a prevalent herpesvirus, with IgG antibodies indicating past infection found in approximately $60 \%$ of adults in developed countries and almost $100 \%$ in developing ones [1]. Although HCMV infection rarely leads to clinical manifestations in immunocompetent hosts, there is an increasing amount of data associating lifelong viral persistence with vascular diseases (atherosclerosis [2], hypertension [3]) and the progression of some cancer types [4]. In addition, HCMV is a major opportunistic pathogen in immunocompromised individuals, posing a serious threat to neonates, allograft recipients and AIDS patients [5]. Perinatal infection can cause irreversible hearing loss, blindness and mental retardation, while immunosuppressed adults may develop multi-organ failure syndrome, which is a life-threatening condition [1,5].

Ganciclovir (GCV) and its orally bioavailable prodrug, Valganciclovir, have served as gold standards for pre-emptive therapy and prophylaxis against HCMV in solid organ transplant patients [6] as well as for the treatment of CMV retinitis [7] for almost 30 years. However, their myelosuppressive potential precludes their prophylactic use in stem cell transplant recipients, which has led to their administration, mostly upon engraftment [8]. In addition, mutations mapping in the gene encoding for the UL97 kinase (responsible for the first phosphorylation of GCV towards its active triphosphate form) and in the UL54 gene encoding for the DNA polymerase (target of ganciclovir triphosphate), have led to the emergence of drug resistant strains [9]. Furthermore, the DNA polymerase inhibitors 
Cidofovir and Foscarnet, which are currently approved as second line agents, have several drawbacks that limit their clinical use, namely severe side effects and poor pharmacokinetic properties [10].

It has become clear that there is an urgent need for better tolerated and more effective antiviral drugs, in order to fully address the health risks posed by HCMV. There are four compounds that have been considered or are at an advanced stage of clinical development for this purpose (Figure 1). Brincidofovir is a per os administered hexadecyloxypropylester of Cidofovir aimed at addressing the parent compound's dose-limiting renal toxicity [11]. The development of Brincidofovir for therapy of HCMV has been halted because of increased gastrointestinal toxicity of the oral formulation in adult hematopoietic cell transplant recipients. The non-nucleoside guanosine analogue Cyclopropavir, which shares the same mechanism of action with GCV, has proven to be more potent in HCMV inhibition in vitro [12] and Phase I trials have been recently completed. Furthermore, the search for novel molecular targets within the viral life cycle has led to the fast track approval of the terminase inhibitor Letermovir in late 2017, for the prophylaxis of HCMV infection and disease in adult HCMV-seropositive recipients of an allogeneic human stem cell transplant (HSCT) [13]. Phase II clinical trials are also about to be launched for the use of Letermovir in paediatric patients who underwent an HSCT.<smiles>CCCCCCCCCCCCOC(=O)OCCCOP(=O)(O)COC(CO)Cn1ccc(N)nc1=O</smiles><smiles>COc1cccc(N2CCN(C3=Nc4c(F)cccc4[C@@H](CC(=O)O)N3c3cc(C(F)(F)F)ccc3OC)CC2)c1</smiles>

Letermovir (AIC246)<smiles>Nc1nc2c(ncn2/C=C2\CC2(CO)CO)c(=O)[nH]1</smiles>

Cyclopropavir (MBX-400) Phase I<smiles>CC(C)Nc1nc2cc(Cl)c(Cl)cc2n1[C@H]1O[C@H](CO)[C@@H](O)[C@H]1O</smiles>

Maribavir (1263W94) Phase III

Figure 1. Recently developed antiviral agents against HCMV.

At the same time, the benzimidazole L-riboside Maribavir is about to be evaluated in Phase III trials involving transplant recipients with HCMV infections that are refractory or resistant to the currently approved drugs as well as for its potential superiority over Valganciclovir in HSCT patients. Maribavir was developed in the late 1990s and has been proven to inhibit viral DNA synthesis as well as nucleocapsid egress from the nucleus via the inhibition of the viral kinase UL97 [14]. However, initial Phase III clinical trials failed to prove sufficient benefits for post-transplant patients. This has later on been accredited to the pre-emptive therapy with GCV that several patients had received prior to surgery and to the low daily administered dose [15].

As a continuation of our previous involvement with the synthesis and evaluation of purine isosteric bioactive nucleosides [16-19], we designed and synthesized a number of novel nucleoside derivatives, which can be considered as 4-(or 7)-aza-D-isosters of Maribavir, having in mind that the D-enantiomer of Maribavir possesses interesting anti-HCMV properties as well [20]. Our goal was to 
expand the structure-activity relationships of the benzimidazole series to the less-studied and more "purine-like" imidazo[4,5-b]pyridine scaffold, retaining the pattern of the 5,6-dichlorosubstitution in the new compounds. The diverse nature of the 2-amino groups in each of the final pair of isomeric nucleosides was at the core of our attempt to explore the spatial limitations of possible target enzymes as well as to gain some insight on potential interactions developed. Within this context, we disclose herein the preparation and pharmacological evaluation of the 1- and 3-regioisomeric $\beta$-D-ribosides of 5,6-dichloroimidazo[4,5-b]pyridine, introducing various amino substituents at the vacant position of the imidazole ring.

\section{Results and Discussion}

\subsection{Chemistry}

The synthetic route we envisaged in order to gain access to the target nucleosides involved the direct glycosylation of the suitably substituted imidazo[4,5-b]pyridines $7 \mathbf{a}-\mathbf{d}$ (Scheme 1). A common intermediate for the synthesis of these derivatives is 5,6-dichloropyridine-2,3-diamine (6), which was prepared following a five-step procedure, previously described by our group, starting from the pyridinamine $\mathbf{1}$ [21].

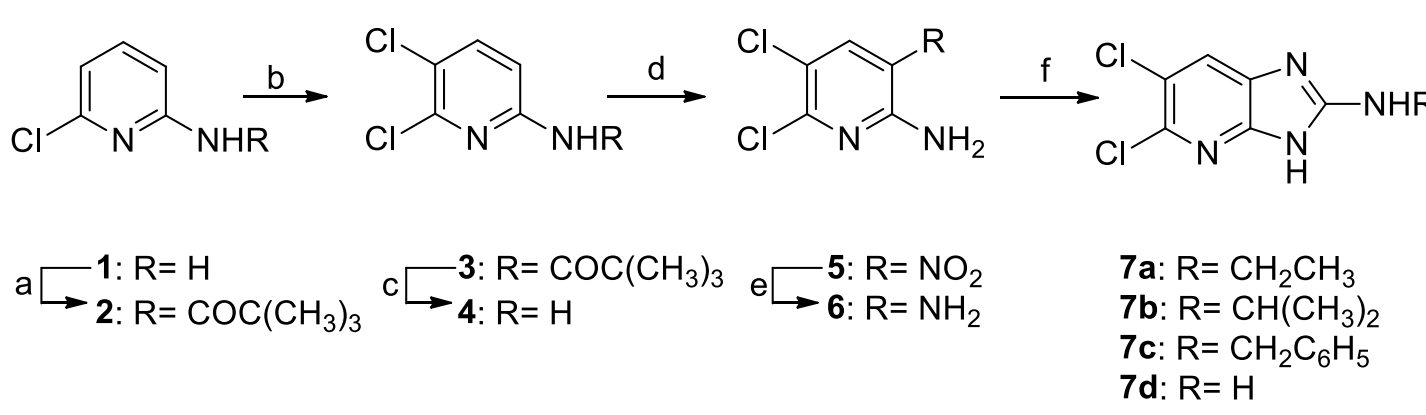

Scheme 1. Reagents and conditions: (a) pivaloyl chloride, $\mathrm{Et}_{3} \mathrm{~N}, \mathrm{DCM}$, r.t., $22 \mathrm{~h}$; (b) NCS, DMF, $100^{\circ} \mathrm{C}$, $18 \mathrm{~h}$; (c) conc. $\mathrm{HCl}, \mathrm{H}_{2} \mathrm{O}, \mathrm{EtOH}$, reflux, $2 \mathrm{~h}$; (d) conc. $\mathrm{HNO}_{3}$, conc. $\mathrm{H}_{2} \mathrm{SO}_{4}$, r.t., 45 min; (e) $\mathrm{SnCl}_{2} \cdot 2 \mathrm{H}_{2} \mathrm{O}$, conc. $\mathrm{HCl}, 60^{\circ} \mathrm{C}, 40 \mathrm{~min}$; (f) (i) $\mathrm{N}$-alkylisothiocyanate, dry THF, reflux, $36 \mathrm{~h}$, (ii) $\mathrm{HgO}$, dry THF, reflux, 40 min for $7 \mathbf{a}-\mathbf{c}$, or $\mathrm{BrCN}, \mathrm{MeOH}, \mathrm{H}_{2} \mathrm{O}, 24 \mathrm{~h}$ for $7 \mathrm{~d}$.

Amino substituted imidazopyridine derivatives $7 \mathbf{a}-\mathbf{c}$ were prepared using a one-pot-two-stage procedure, which involves an initial treatment of 6 with appropriately substituted $\mathrm{N}$-alkylisothiocyanates in refluxing THF. The resulting mixture of isomeric thioureas undergoes rapid cyclodesulfurization in the presence of mercury oxide [22], yielding compounds 7a-c. Concerning the preparation of the primary aminoderivative $\mathbf{7 d}$, we implemented a different approach, which had been previously reported by Townsend [23], for the synthesis of the corresponding benzimidazole analogue. Thus, the addition of cyanogen bromide in a suspension of diamine 6 in a 1:1 mixture of $\mathrm{MeOH}$ and water provided $\mathbf{7 d}$ as the sole reaction product in very good yield.

The target N1- and N3-ribonucleoside acetates were prepared under modified Vorbrüggen conditions. The in situ formation of the persilylated heterocyclic bases by treatment of the corresponding heterocyclic compounds $7 \mathbf{a}-\mathbf{d}$ with $\mathrm{N}, \mathrm{O}$-bistrimethylsilylacetamide (BSA) was followed by the addition of peracetylated $\beta$-D-ribofuranose and trimethylsilyltrifluoromethanesulfonate (TMSOTf) (Scheme 2). Thus, concerning the glycosylation reaction of compounds $7 \mathbf{a}-\mathbf{c}$, the major products isolated were the $3-\beta$-D-ribosides $\mathbf{8 a - \mathbf { c }}$, as a mixture with a small amount of the corresponding $\alpha$-anomers $\mathbf{9 a}-\mathbf{c}$. The $N 1$ regioisomers were also obtained as mixtures of the 1- $\beta$-D ribosides $10 \mathrm{a}-\mathbf{c}$ with their corresponding $\alpha-\mathrm{D}$ anomers 11a-c. 


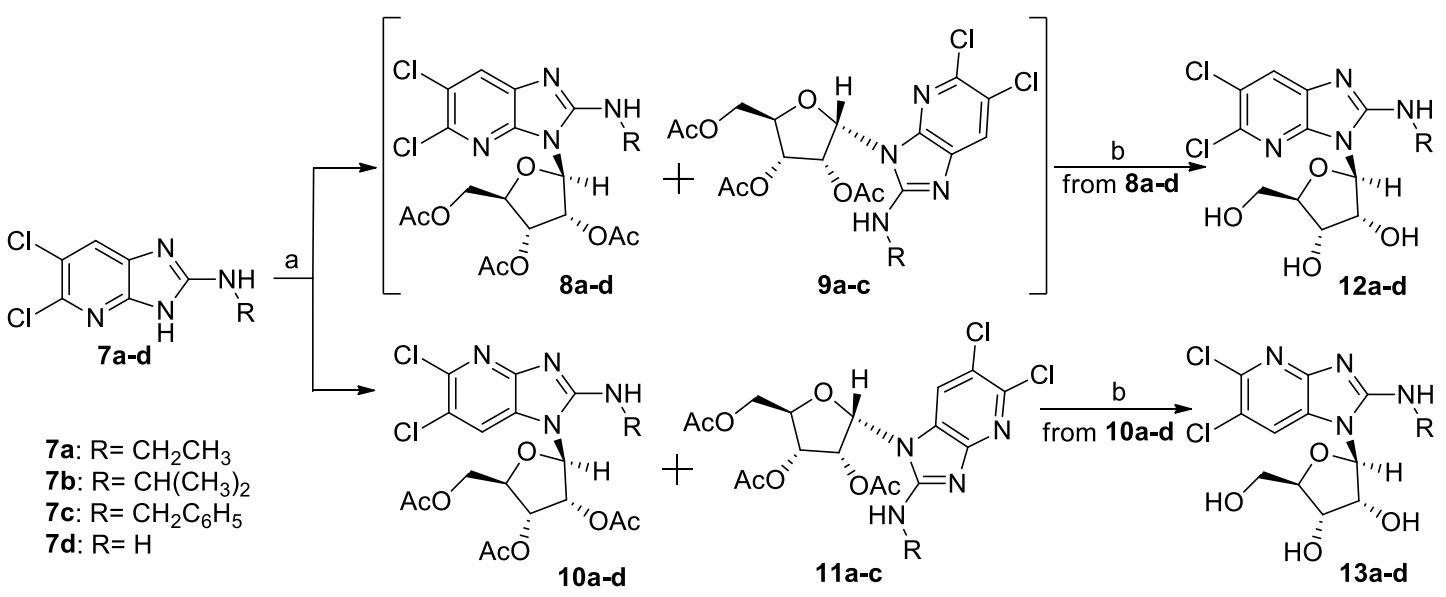

Scheme 2. Reagents and conditions: (a) (i) N,O-bis(trimethylsilyl)acetamide, ACN, reflux, 2h, (ii) tetra-O-acetyl- $\beta$-D-ribofuranose, TMSOTf, reflux, 3h; (b) $\mathrm{NH}_{3(\mathrm{~g})}, \mathrm{MeOH}, \mathrm{rt}, 18 \mathrm{~h}$.

Regarding the $N 1$ regioisomers, we were able to isolate pure $N 1-\beta$-D nucleoside acetates $10 \mathbf{a}-\mathbf{c}$ as well as their corresponding $N 1-\alpha-\mathrm{D}$ anomers 11a-c, upon chromatographic purification. The site of ribosylation as well as the anomeric configuration were unambiguously determined on the basis of NOE spectroscopy. Taking into consideration the NOE spectra of compounds 10a-c and 11a-c, we observed clear correlation peaks between the aromatic proton and protons of the furanose ring, determinant of the N1-ribosylation pattern. In addition, we also noticed cross correlation peaks between $1^{\prime}-\mathrm{H}$ and $4^{\prime}-\mathrm{H}$ of the sugar moiety in the spectra of compounds $10 \mathrm{a}-\mathrm{c}$. Such peaks were not observed on the NOE spectra of 11a-c, thus clearly concluding that 11a-c were the $N 1-\alpha$-D nucleoside products of the reaction, while 10a-c were their corresponding $\beta$-D anomers. Deacetylation of 10a-c with methanolic ammonia provided the final compounds $\mathbf{1 3} \mathbf{a}-\mathbf{c}$.

Isolation of the pure 3- $\beta$-D nucleoside acetates proved to be difficult at this stage, so the mixtures of $8 \mathbf{a}-\mathbf{c}$ with their corresponding $\alpha$-anomers $9 \mathbf{a}-\mathbf{c}$ were subjected to ammoniolysis, to provide the deprotected nucleosides. The ethylamino (12a) and isopropylamino (12b) derivatives were isolated in pure form by recrystallization, whereas an analytically pure sample of the benzylamino compound $\mathbf{1 2 c}$ was obtained upon purification with semi-preparative HPLC. Anomeric purity and configuration of compounds 12a-c were determined on the basis of ${ }^{1} \mathrm{H}-\mathrm{NMR}$ and NOE spectra, respectively. In the latter ones, we observed clear correlation peaks between $1^{\prime}-\mathrm{H}$ and $4^{\prime}-\mathrm{H}$ of the ribofuranose moiety, while there was a profound absence of correlation peaks between the aromatic and sugar protons on the NOE spectra of each of the aforementioned compounds. The close examination of 1D and 2D NMR spectra reveals that a simple differentiation between each pair of regio isomers can be easily made upon inspection of the chemical shift of the aromatic proton. This proton appears upfield in the case of the N3-isomers 12a-d (7.7-7.8 ppm) whereas it shifts downfield (8.0-8.1 ppm) concerning the N1-isomers 13a-d.

Applying the same reaction conditions for the glycosylation of the primary aminoderivative $7 \mathrm{~d}$, we isolated from the reaction mixture the $3-\beta$-D nucleoside acetate (8d), as well as the $1-\beta$-D isomer (10d), without detectable amounts of the corresponding $\alpha$-anomers. Deprotection of $\mathbf{8 d}$ and $\mathbf{1 0 d}$ with methanolic ammonia provided the respective final ribosides $\mathbf{1 2} \mathrm{d}$ and $\mathbf{1 3 d}$. However, the major product of the glycosylation reaction of $\mathbf{7 d}$ turned out to be the di-ribosylated compound $\mathbf{1 4}$ (Figure 2), whose structure was elucidated on the basis of ${ }^{1} \mathrm{H}-\mathrm{NMR},{ }^{13} \mathrm{C}-\mathrm{NMR}, \mathrm{NOE}$ and mass spectra. Two sets of sugar carbon peaks were observed on the ${ }^{13} \mathrm{C}-\mathrm{NMR}$ spectrum of $\mathbf{1 4}$, in the presence of only one set of aromatic carbon peaks. The sites of substitution as well as the anomeric configuration were assigned as exemplified in Figure 2 (namely $N, 1-\beta-D$ ). Upon careful examination of the NOE spectrum of 14, we observed a set of correlation peaks between the aromatic proton and protons of one sugar moiety as well as correlation peaks between the anomeric proton of each furanose with its corresponding $4^{\prime}$-proton. 


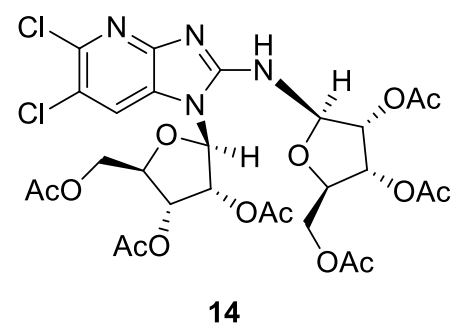

Figure 2. Structure of di-ribosylated by-product formed upon glycosylation of the amino derivative 7d.

\subsection{Biological Evaluation}

Compounds 12a-d and 13a-d were evaluated for their activity against Vaccinia virus, Adeno virus-2, Human Coronavirus (229E), HSV-1, HSV-2, VZV, and HCMV (AD-169 and Davis strains) in human embryonic lung cell cultures (HEL) (Tables S1-S3). Unfortunately, the new derivatives proved to lack antiviral activity against all viruses tested. In particular, the substitution of the benzimidazole pharmacophore present in Maribavir by the imidazo[4,5-b]pyridine scaffold, in combination with the replacement of the L-sugar configuration with its corresponding D-riboside, resulted in total loss of the anti-HCMV activity. Nevertheless, upon determination of the cytotoxic properties of the new derivatives, compounds $\mathbf{1 2 c}, \mathbf{1 2} \mathrm{d}$ and $\mathbf{1 3}$, proved to possess moderate antiproliferative activity against the three cancer cell lines tested, namely human T-lymphocyte cells (CEM), human cervix carcinoma cells (HeLa) and human dermal microvascular endothelial cells (HMEC-1) (Table S4). Among these compounds, both 2-benzylamino-substituted derivatives 12c and 13c showed antiproliferative activity against $\mathrm{CEM}$ cell-line, with equipotent $\mathrm{IC}_{50}$ values $(37 \pm 3$ and $39 \pm 8 \mu \mathrm{M})$ and at the same time, 12c proved active in inhibiting the growth of HeLa and HMEC-1 cell lines, possessing $\mathrm{IC}_{50}$ values of $36 \pm 7 \mu \mathrm{M}$ and $20 \pm 2 \mu \mathrm{M}$, respectively. The increased antiproliferative effects of $\mathbf{1 2 c}$ and $\mathbf{1 3 c}$ are worth investigating further and are currently under active search in our laboratories.

\section{Materials and Methods}

\subsection{General Information}

Tetrahydrofuran (THF) was distilled from sodium/benzophenone ketyl immediately prior to use. Melting points were determined on a Büchi apparatus and are uncorrected. ${ }^{1} \mathrm{H}-\mathrm{NMR}$ spectra and ${ }^{2} \mathrm{D}$ (COSY, NOESY, HSQC, HMBC) NMR spectra were recorded on a Bruker Avance III 600 or a Bruker Avance (Bruker, Karlsruhe, Germany) DRX 400 instrument, whereas ${ }^{13} \mathrm{C}-\mathrm{NMR}$ spectra were recorded on a Bruker Avance III 600 in deuterated solvents and were referenced to TMS ( $\delta$ scale). The signals of ${ }^{1} \mathrm{H}$ and ${ }^{13} \mathrm{C}$ spectra were unambiguously assigned by using 2D NMR techniques: ${ }^{1} \mathrm{H}^{1} \mathrm{H}$ COSY, NOESY, HSQC and HMBC. Mass spectra were recorded with a LTQ Orbitrap Discovery instrument, possessing an Ionmax ionization source. Column chromatography was performed on Merck (Merk, Darmstadt, Germany) silica gel $60(0.040-0.063 \mathrm{~mm})$, unless specified otherwise. Analytical thin layer chromatography (TLC) was carried out on precoated $(0.25 \mathrm{~mm})$ Merck silica gel F-254 plates. Preparative HPLC was performed on a system equipped with two Prep LabAlliance pumps (ASI, Richmond, CA, USA), a Fortis C-18 $(5 \mu \mathrm{m})$ column (i.d. $10 \times 250 \mathrm{~mm}$ ) and a FLASH 06S DAD 600 detector (ECOM, Praha, Czech Republic). Optical rotations were obtained on a Perkin-Elmer 341 Polarimeter (Perkin Elmer, Shelton, CT, USA).

\subsection{Synthesis}

5,6-Dichloro- $N$-ethyl-3H-imidazo[4,5-b]pyridin-2-amine(7a): Ethylisothiocyanate (1 mL, 11.24 $\mathrm{mmol}$ ) was added to a solution of diamine $6(500 \mathrm{mg}, 2.81 \mathrm{mmol})$ in anhydrous THF $(10 \mathrm{~mL})$ and the reaction mixture was refluxed under argon for $36 \mathrm{~h}$. The mixture was then cooled to room temperature and $\mathrm{HgO}(1.22 \mathrm{~g}, 5.65 \mathrm{mmol})$ was added, leading to an orange suspension. Refluxing the reaction mixture resulted progressively in a black coloured suspension and within $40 \mathrm{~min}$ the reaction was 
completed. The mixture was filtered warm through a celite pad, which was thoroughly washed with warm $\mathrm{MeOH}$. The solvent was then vacuum-evaporated and the residue was purified by column chromatography using a mixture of $\mathrm{CHCl}_{3} / \mathrm{MeOH}(95 / 5$ to $85 / 15, v / v)$ as the eluent, to result in $340 \mathrm{mg}$ of $7 \mathbf{a}\left(52 \%\right.$ overall yield). Beige solid, $\mathrm{mp}>300{ }^{\circ} \mathrm{C}(\mathrm{dec}),(\mathrm{MeOH}) .{ }^{1} \mathrm{H}-\mathrm{NMR}\left(\mathrm{DMSO}-d_{6}, 600 \mathrm{MHz}\right) \delta 1.16$ $\left(\mathrm{t}, 3 \mathrm{H}, \mathrm{CH}_{3}, J=7.2 \mathrm{~Hz}\right), 3.33\left(\mathrm{~m}, 2 \mathrm{H}, \mathrm{CH}_{2}\right), 7.37$ (br s, $1 \mathrm{H}, \mathrm{D}_{2} \mathrm{O}$ exchangeable, $\left.\mathrm{NH}\right), 7.57$ (s, 1H, H-7). ${ }^{13} \mathrm{C}-\mathrm{NMR}\left(151 \mathrm{MHz}, \mathrm{DMSO}-d_{6}\right) \delta 14.87\left(\mathrm{CH}_{3}\right), 36.82\left(\mathrm{CH}_{2}\right), 116.40(\mathrm{C}-6), 116.58(\mathrm{C}-7$, major tautomeric form), 121.73 (C-7, minor tautomeric form), 126.92 (C-7a), 137.46 (C-5), 156.20 (C-3a), 158.92 (C-2). HR-MS (ESI) $m / z$ : Calcd for $\mathrm{C}_{8} \mathrm{H}_{9} \mathrm{Cl}_{2} \mathrm{~N}_{4}:[\mathrm{M}+\mathrm{H}]^{+}=231.0199$, found 231.0202.

5,6-Dichloro- $N$-isopropyl-3H-imidazo[4,5-b]pyridin-2-amine (7b):This compound was prepared by a procedure analogous to that described for 7a, upon reaction of diamine 6 (500 $\mathrm{mg}, 2.81 \mathrm{mmol}$ ) with isopropyl isothiocyanate $(0.90 \mathrm{~mL}, 8.43 \mathrm{mmol})$. Purification was effected by column chromatography, using a mixture of DCM/EtOAc (70/30 to 20/80, v/v) and then EtOAc/MeOH (99/1 to 97/3, v/v) as eluents. Overall yield 55\%. White solid, mp $235-236{ }^{\circ} \mathrm{C}$ (acetone). ${ }^{1} \mathrm{H}-\mathrm{NMR}\left(600 \mathrm{MHz}, \mathrm{DMSO}-d_{6}\right) \delta 1.20(\mathrm{~d}$, $\left.6 \mathrm{H}, 2 \mathrm{CCH}_{3}, \mathrm{~J}=6.1 \mathrm{~Hz}\right), 3.92(\mathrm{~m}, 1 \mathrm{H}, \mathrm{CH}), 7.34$ (br s, 1H, $\mathrm{D}_{2} \mathrm{O}$ exchangeable, $\left.\mathrm{NH}\right), 7.56(\mathrm{~s}, 1 \mathrm{H}, \mathrm{H}-7)$, 11.06 (br s, $1 \mathrm{H}, \mathrm{D}_{2} \mathrm{O}$ exchangeable, imidazole $\mathrm{NH}$ of the major tautomeric form), 11.66 (br s, $1 \mathrm{H}, \mathrm{D}_{2} \mathrm{O}$ exchangeable, imidazole NH of the minor tautomeric form). ${ }^{13} \mathrm{C}-\mathrm{NMR}\left(151 \mathrm{MHz}, \mathrm{DMSO}-d_{6}\right) \delta 22.58$ $\left(\mathrm{CH}_{3}\right), 43.97(\mathrm{CH}), 116.37(\mathrm{C}-6), 116.61$ (C-7 of the major tautomeric form), 121.62 (C-7 of the minor tautomeric form), 126.86 (C-7a), 137.41 (C-5), 156.22 (C-3a), 158.24 (C-2). HR-MS (ESI) m/z: Calcd for $\mathrm{C}_{9} \mathrm{H}_{11} \mathrm{Cl}_{2} \mathrm{~N}_{4}:[\mathrm{M}+\mathrm{H}]^{+}=245.0355$, found 245.0352 .

$\mathrm{N}$-Benzyl-5,6-dichloro-3H-imidazo[4,5-b]pyridin-2-amine (7c): This compound was prepared by a procedure analogous to that described for 7a, upon reaction of diamine 6 (500 $\mathrm{mg}, 2.81 \mathrm{mmol})$ with benzyl isothiocyanate $(0.80 \mathrm{~mL}, 6.03 \mathrm{mmol})$. Purification was effected by column chromatography, using a mixture of DCM/EtOAc (90/10 to 50/50, v/v) and then EtOAc/MeOH (99/1 to 90/10, v/v) as eluents. Overall yield 51\%. White solid, mp: $277-278{ }^{\circ} \mathrm{C}(\mathrm{MeOH}) .{ }^{1} \mathrm{H}-\mathrm{NMR}\left(600 \mathrm{MHz}, \mathrm{DMSO}-d_{6}\right) \delta$

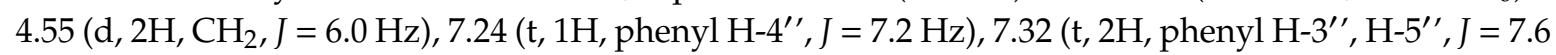
$\mathrm{Hz}$ ), 7.36 (d, 2H, phenyl H-2' ', H-6" ', J = $7.3 \mathrm{~Hz}$ ), 7.60 (s, 1H, H-7), 7.94 (br s, 1H, $\mathrm{D}_{2} \mathrm{O}$ exchangeable, $\mathrm{NH}), 11.38$ (br s, 1H, D $2 \mathrm{O}$ exchangeable, imidazole NH). ${ }^{13} \mathrm{C}-\mathrm{NMR}\left(151 \mathrm{MHz}, \mathrm{DMSO}-d_{6}\right) \delta 45.36$ $\left(\mathrm{CH}_{2}\right), 116.89$ (C-6), 117.05 (C-7), 126.97 (phenyl C-4' $), 127.13$ (C-7a), 127.25 (phenyl C-3' ', C-5' $), 128.33$ (phenyl C-2' ${ }^{\prime \prime}$ C-6" ${ }^{\prime}$ ), 137.50 (C-5), 139.34 (phenyl C-1' '), 155.88 (C-3a), 158.81 (C-2). HR-MS (ESI) m/z: Calcd for $\mathrm{C}_{13} \mathrm{H}_{11} \mathrm{Cl}_{2} \mathrm{~N}_{4}:[\mathrm{M}+\mathrm{H}]^{+}=293.0355$, found 293.0358.

5,6-Dichloro-3H-imidazo[4,5-b]pyridin-2-amine (7d): To a suspension of the diamine 6 (570 mg, $3.20 \mathrm{mmol})$ in $\mathrm{MeOH}(12 \mathrm{~mL})$ and $\mathrm{H}_{2} \mathrm{O}(12 \mathrm{~mL})$ was added $\mathrm{BrCN}(1.60 \mathrm{~mL}, 5 \mathrm{M}$ solution in acetonitrile, $8 \mathrm{mmol}$ ) and the reaction mixture was stirred at room temperature for $48 \mathrm{~h}$. MeOH was concentrated under vacuo and the $\mathrm{pH}$ of the resulting aqueous phase was adjusted to 8 with a saturated $\mathrm{NaHCO}_{3}$ solution. The aqueous layer $(150 \mathrm{~mL})$ was extracted with EtOAc $(5 \times 200 \mathrm{~mL})$ and the combined organic layers were dried (anhydrous $\mathrm{Na}_{2} \mathrm{SO}_{4}$ ) and concentrated to dryness. The residue thus obtained was triturated with diethyl ether to afford $510 \mathrm{mg}$ of $\mathbf{7 d}$ as an amorphous solid $(79 \%)$. ${ }^{1} \mathrm{H}-\mathrm{NMR}$ (DMSO- $d_{6}$, $600 \mathrm{MHz}) \delta 7.05$ (br s, 2H, $\mathrm{D}_{2} \mathrm{O}$ exchangeable, $\left.\mathrm{NH}_{2}\right), 7.58$ (s, 1H, H-7). ${ }^{13} \mathrm{C}-\mathrm{NMR}\left(151 \mathrm{MHz}, \mathrm{DMSO}-d_{6}\right)$ $\delta 117.54$ (C-6), 118.24 (C-7), 129.57 (C-7a), 136.73 (C-5), 153.60 (C-3a), 158.85 (C-2). HR-MS (ESI) m/z: Calcd for $\mathrm{C}_{6} \mathrm{H}_{5} \mathrm{Cl}_{2} \mathrm{~N}_{4}:[\mathrm{M}+\mathrm{H}]^{+}=202.9886$, found 202.9887 .

5,6-Dichloro- $\mathrm{N}$-ethyl-3-(2' $3^{\prime}, 5^{\prime}$-tri-O-acetyl- $\beta$-D-ribofuranosyl)-3H-imidazo[4,5-b]pyridin-2-amine (8a), 5,6-dichloro- $N$-ethyl-3-(2', 3', 5' -tri-O-acetyl- $\alpha$-D-ribofuranosyl)-3H-imidazo[4,5-b]pyridin-2-amine (9a), 5,6-dichloro- $N$-ethyl-1-(2', $3^{\prime}, 5^{\prime}$-tri-O-acetyl- $\beta$-D-ribofuranosyl)- $1 H$-imidazo[4,5-b]pyridin-2-amine (10a) and 5,6-dichloro- $N$-ethyl-1-(2', $3^{\prime}, 5^{\prime}$-tri-O-acetyl- $\alpha$-D-ribofuranosyl)- $1 H$-imidazo[4,5-b]pyridin-2-amine (11a): To a suspension of the imidazopyridine $7 \mathbf{a}(250 \mathrm{mg}, 1.08 \mathrm{mmol})$ in dry $\mathrm{CH}_{3} \mathrm{CN}(10 \mathrm{~mL})$ was added $\mathrm{N}, \mathrm{O}$-bis-(trimethylsilyl)acetamide $(291 \mathrm{mg}, 1.43 \mathrm{mmol}$ ) and the reaction mixture was refluxed for $2 \mathrm{~h}$. The suspension was then cooled to room temperature and 1,2,3,5-tetra- $O$-acetyl- $\beta$-D-ribofuranose (413 mg, 1.30 mmol) was added, followed by the dropwise addition of trimethylsilyltriflate $(0.3 \mathrm{~mL}, 1.54 \mathrm{mmol})$ at $0{ }^{\circ} \mathrm{C}$. The mixture was refluxed for $3 \mathrm{~h}$, the solvent was vacuum evaporated, the residue was dissolved in EtOAc $(100 \mathrm{~mL})$ and washed with a saturated $\mathrm{NaHCO}_{3}$ solution $(100 \mathrm{~mL})$. The aqueous phase was extracted once 
more with EtOAc $(100 \mathrm{~mL})$ and the combined organic layers were washed with brine $(200 \mathrm{~mL})$, dried $\left(\mathrm{Na}_{2} \mathrm{SO}_{4}\right)$ and evaporated to dryness. The resulting oil was purified by column chromatography, using a mixture of $\mathrm{CHCl}_{3} / \mathrm{MeOH}(99 / 1$ to $97 / 3, v / v)$ as the eluent, to afford $\mathbf{8 a}$, as a mixture with its corresponding $\alpha$-anomer 9a (280 mg, total yield 53\% for two anomers, 8a:9a (3- $\beta: \alpha)$ ratio 12:1, as estimated by $\left.{ }^{1} \mathrm{H}-\mathrm{NMR}\right)$, 10a (115 mg, yield 22\%) and 11a (27 mg, yield 5\%).

Data for 10a: Oil, $[\alpha]_{\mathrm{D}}+30.55\left(c=0.475, \mathrm{CHCl}_{3}\right) .{ }^{1} \mathrm{H}-\mathrm{NMR}\left(600 \mathrm{MHz}, \mathrm{CDCl}_{3}\right) \delta 1.32\left(\mathrm{t}, 3 \mathrm{H}, \mathrm{CH}_{3}\right.$, $J=7.1 \mathrm{~Hz}), 2.04\left(\mathrm{~s}, 3 \mathrm{H}, \mathrm{CH}_{3} \mathrm{CO}\right), 2.17\left(\mathrm{~s}, 3 \mathrm{H}, \mathrm{CH}_{3} \mathrm{CO}\right), 2.20\left(\mathrm{~s}, 3 \mathrm{H}, \mathrm{CH}_{3} \mathrm{CO}\right), 3.59\left(\mathrm{~m}, 1 \mathrm{H}, \mathrm{CH}_{2}\right), 3.67(\mathrm{~m}$, $\left.1 \mathrm{H}, \mathrm{CH}_{2}\right), 4.34\left(\mathrm{dd}, 1 \mathrm{H}, \mathrm{H}-5^{\prime}, J_{5^{\prime}, 4^{\prime}}=2.2 \mathrm{~Hz}, J_{5^{\prime}, 5^{\prime}}=12.7 \mathrm{~Hz}\right), 4.41\left(\mathrm{~m}, 1 \mathrm{H}, \mathrm{H}-4^{\prime}\right), 4.65\left(\mathrm{dd}, 1 \mathrm{H}, \mathrm{H}-5^{\prime}\right.$, $\left.J_{5^{\prime}, 4^{\prime}}=3.8 \mathrm{~Hz}, J_{5^{\prime}, 5^{\prime}}=12.7 \mathrm{~Hz}\right), 5.31\left(\mathrm{dd}, 1 \mathrm{H}, \mathrm{H}-3^{\prime}, J_{3^{\prime}, 4^{\prime}}=3.6 \mathrm{~Hz}, J_{3^{\prime}, 2^{\prime}}=6.2 \mathrm{~Hz}\right), 5.35\left(\mathrm{~m}, 1 \mathrm{H}, \mathrm{H}-2^{\prime}\right)$, $5.98\left(\mathrm{~d}, 1 \mathrm{H}, \mathrm{H}-1^{\prime}, J_{1^{\prime}, 2^{\prime}}=6.5 \mathrm{~Hz}\right), 6.13\left(\mathrm{br} \mathrm{s}, 1 \mathrm{H}, \mathrm{D}_{2} \mathrm{O}\right.$ exchangeable, $\left.\mathrm{NH}\right), 7.52(\mathrm{~s}, 1 \mathrm{H}, \mathrm{H}-7) .{ }^{13} \mathrm{C}-\mathrm{NMR}$ $\left(151 \mathrm{MHz}, \mathrm{CDCl}_{3}\right) \delta 15.03\left(\mathrm{CH}_{3}\right), 20.42\left(\mathrm{CH}_{3} \mathrm{CO}\right), 20.69\left(\mathrm{CH}_{3} \mathrm{CO}\right), 20.93\left(\mathrm{CH}_{3} \mathrm{CO}\right), 38.92\left(\mathrm{CH}_{2}\right), 62.85$ $\left(\mathrm{C}-5^{\prime}\right), 69.67\left(\mathrm{C}-3^{\prime}\right), 71.61\left(\mathrm{C}-2^{\prime}\right), 81.18\left(\mathrm{C}-4^{\prime}\right), 86.35$ (C-1'), 117.71 (C-7), 120.20 (C-6), 125.61 (C-7a), 141.57 (C-5), 153.55 (C-3 $\alpha), 156.43$ (C-2), 169.49 (CO), 169.78 (CO), 170.26 (CO). HR-MS (ESI) m/z: Calcd for $\mathrm{C}_{19} \mathrm{H}_{22} \mathrm{Cl}_{2} \mathrm{~N}_{4} \mathrm{O}_{7} \mathrm{Na}:[\mathrm{M}+\mathrm{Na}]^{+}=511.0758$, found 511.0762 .

Data for 11a: Oil, $[\alpha]_{\mathrm{D}}+61.23\left(c=0.684, \mathrm{CHCl}_{3}\right) .{ }^{1} \mathrm{H}-\mathrm{NMR}\left(600 \mathrm{MHz}, \mathrm{CDCl}_{3}\right) \delta 1.28\left(\mathrm{t}, 3 \mathrm{H}, \mathrm{CH}_{3}\right.$, $J=7.2 \mathrm{~Hz}), 1.82$ (s, 3H, $\left.\mathrm{CH}_{3} \mathrm{CO}\right), 2.11\left(\mathrm{~s}, 3 \mathrm{H}, \mathrm{CH}_{3} \mathrm{CO}\right), 2.15\left(\mathrm{~s}, 3 \mathrm{H}, \mathrm{CH}_{3} \mathrm{CO}\right), 3.57\left(\mathrm{~m}, 2 \mathrm{H}, \mathrm{CH}_{2}\right), 4.29(\mathrm{dd}$, $\left.1 \mathrm{H}, \mathrm{H}-5^{\prime}, J_{5^{\prime}}, 4^{\prime}=4.9 \mathrm{~Hz}, J_{5^{\prime}, 5^{\prime}}=12.3 \mathrm{~Hz}\right), 4.33\left(\mathrm{dd}, 1 \mathrm{H}, \mathrm{H}-5^{\prime}, J_{5^{\prime}}, 4^{\prime}=3.5 \mathrm{~Hz}, J_{5^{\prime}, 5^{\prime}}=12.3 \mathrm{~Hz}\right), 4.66(\mathrm{~m}, 1 \mathrm{H}$, $\left.\mathrm{H}-4^{\prime}\right), 5.27\left(\mathrm{t}, 1 \mathrm{H}, \mathrm{D}_{2} \mathrm{O}\right.$ exchangeable, $\left.\mathrm{NH}, J=5.3 \mathrm{~Hz}\right), 5.45\left(\mathrm{t}, 1 \mathrm{H}, \mathrm{H}-3^{\prime}, J=5.3 \mathrm{~Hz}\right), 5.73\left(\mathrm{t}, 1 \mathrm{H}, \mathrm{H}-2^{\prime}\right.$, $J=5.1 \mathrm{~Hz}), 6.19\left(\mathrm{~d}, 1 \mathrm{H}, \mathrm{H}-1^{\prime}, J_{1^{\prime}, 2^{\prime}}=4.9 \mathrm{~Hz}\right), 7.55(\mathrm{~s}, 1 \mathrm{H}, \mathrm{H}-7) .{ }^{13} \mathrm{C}-\mathrm{NMR}\left(151 \mathrm{MHz}, \mathrm{CDCl}_{3}\right) \delta 14.96$ $\left(\mathrm{CH}_{3}\right), 20.28\left(\mathrm{CH}_{3} \mathrm{CO}\right), 20.55\left(\mathrm{CH}_{3} \mathrm{CO}\right), 20.94\left(\mathrm{CH}_{3} \mathrm{CO}\right), 38.71\left(\mathrm{CH}_{2}\right), 63.31\left(\mathrm{C}-5^{\prime}\right), 71.08\left(\mathrm{C}-3^{\prime}\right), 71.55$

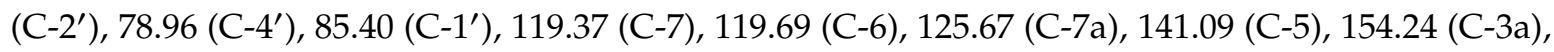
157.01 (C-2), 169.26 (CO), 169.55 (CO), 170.51 (CO). HR-MS (ESI) m/z: Calcd for $\mathrm{C}_{19} \mathrm{H}_{22} \mathrm{Cl}_{2} \mathrm{~N}_{4} \mathrm{O}_{7} \mathrm{Na}$ : $[\mathrm{M}$ $+\mathrm{Na}]^{+}=511.0758$, found 511.0764 .

5,6-Dichloro- $N$-isopropyl-3-(2', 3', 5' -tri-O-acetyl- $\beta$-D-ribofuranosyl)-3H-imidazo[4,5-b]pyridin-2amine (8b), 5,6-dichloro- $N$-isopropyl-3-(2', $3^{\prime}, 5^{\prime}$-tri-O-acetyl- $\alpha$-D-ribofuranosyl)-3H-imidazo[4,5b]pyridin-2-amine (9b), 5,6-dichloro- $N$-isopropyl-1-(2', $3^{\prime}, 5^{\prime}$-tri-O-acetyl- $\beta$-D-ribofuranosyl)- $1 H$ imidazo[4,5-b]pyridin-2-amine $\mathbf{( 1 0 b )}$ and 5,6-dichloro- $N$-isopropyl-1- $\left(2^{\prime}, 3^{\prime}, 5^{\prime}\right.$-tri-O-acetyl- $\alpha$ - $D$ ribofuranosyl)-1H-imidazo[4,5-b]pyridin-2-amine (11b): These derivatives were prepared by a procedure analogous to that described for $\mathbf{8 a}, \mathbf{9 a}, \mathbf{1 0 a}, \mathbf{1 1 a}$, starting from imidazopyridine $\mathbf{7 b}(280 \mathrm{mg}$, $1.14 \mathrm{mmol})$. Purification was effected by column chromatography, using a mixture of $\mathrm{CHCl}_{3} / \mathrm{MeOH}^{-}$ $(99.5 / 0.5$ to $98 / 2, v / v)$ as the eluent, to afford $\mathbf{8 b}$, as a mixture with its corresponding $\alpha$-anomer $\mathbf{9 b}$ (350 $\mathrm{mg}, 61 \%$ total yield for two anomers, $8 \mathrm{~b}: 9 \mathrm{~b}(3-\beta: \alpha)$ ratio $24: 1$, as estimated by $\left.{ }^{1} \mathrm{H}-\mathrm{NMR}\right), 10 \mathrm{~b}(140 \mathrm{mg}$, $24 \%$ yield) and $\mathbf{1 1 b}$ (50 $\mathrm{mg}, 9 \%$ yield).

Data for 10b: Beige solid, mp: $165-166{ }^{\circ} \mathrm{C}$ (EtOAc/n-pentane). $[\alpha]_{\mathrm{D}}+37.77\left(c=0.495, \mathrm{CHCl}_{3}\right) \cdot{ }^{1} \mathrm{H}$ NMR $\left(600 \mathrm{MHz}, \mathrm{CDCl}_{3}\right) \delta 1.30\left(\mathrm{~d}, 3 \mathrm{H}, \mathrm{CH}_{3}, J=6.5 \mathrm{~Hz}\right), 1.31\left(\mathrm{~d}, 3 \mathrm{H}, \mathrm{CH}_{3}, J=6.5 \mathrm{~Hz}\right), 2.04(\mathrm{~s}, 3 \mathrm{H}$, $\left.\mathrm{CH}_{3} \mathrm{CO}\right), 2.15$ (s, 3H, CH $\left.3 \mathrm{CO}\right), 2.19$ (s, 3H, CH $\left.3 \mathrm{CO}\right), 4.27$ (m, 1H, CH), $4.32\left(\mathrm{dd}, 1 \mathrm{H}, \mathrm{H}-5^{\prime}, J_{5^{\prime}}, 4^{\prime}=2.2 \mathrm{~Hz}\right.$, $\left.J_{5^{\prime}, 5^{\prime}}=12.7 \mathrm{~Hz}\right), 4.39\left(\mathrm{~m}, 1 \mathrm{H}, \mathrm{H}-4^{\prime}\right), 4.62\left(\mathrm{dd}, 1 \mathrm{H}, \mathrm{H}-5^{\prime}, J_{5^{\prime}}, 4^{\prime}=4.0 \mathrm{~Hz}, J_{5^{\prime}, 5^{\prime}}=12.7 \mathrm{~Hz}\right), 5.30\left(\mathrm{dd}, 1 \mathrm{H}, \mathrm{H}-3^{\prime}\right.$, $\left.J_{3^{\prime}, 4^{\prime}}=3.6 \mathrm{~Hz}, J_{3^{\prime}, 2^{\prime}}=6.1 \mathrm{~Hz}\right), 5.33\left(\mathrm{~m}, 1 \mathrm{H}, \mathrm{H}-2^{\prime}\right), 5.47\left(\right.$ br s, $1 \mathrm{H}, \mathrm{D}_{2} \mathrm{O}$ exchangeable, NH), $5.86(\mathrm{~d}, 1 \mathrm{H}$, $\left.\mathrm{H}-1^{\prime}, J_{1^{\prime}, 2^{\prime}}=6.7 \mathrm{~Hz}\right), 7.53(\mathrm{~s}, 1 \mathrm{H}, \mathrm{H}-7) .{ }^{13} \mathrm{C}-\mathrm{NMR}\left(151 \mathrm{MHz}, \mathrm{CDCl}_{3}\right) \delta 20.41\left(\mathrm{CH}_{3} \mathrm{CO}\right), 20.67\left(\mathrm{CH}_{3} \mathrm{CO}\right)$, $21.04\left(\mathrm{CH}_{3} \mathrm{CO}\right), 22.76\left(\mathrm{CH}_{3}\right), 23.03\left(\mathrm{CH}_{3}\right), 46.04(\mathrm{CH}), 62.80\left(\mathrm{C}-5^{\prime}\right), 69.59\left(\mathrm{C}-3^{\prime}\right), 71.87\left(\mathrm{C}-2^{\prime}\right), 81.06\left(\mathrm{C}-4^{\prime}\right)$,

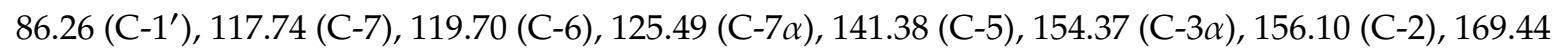
(CO), 169.72 (CO), 170.29 (CO). HR-MS (ESI) $m / z$ : Calcd for $\mathrm{C}_{20} \mathrm{H}_{24} \mathrm{Cl}_{2} \mathrm{~N}_{4} \mathrm{O}_{7} \mathrm{Na}:[\mathrm{M}+\mathrm{Na}]^{+}=525.0914$, found 525.0917 .

Data for 11b: Oil, $[\alpha]_{\mathrm{D}}+57.75\left(c=0.561, \mathrm{CHCl}_{3}\right) .{ }^{1} \mathrm{H} \mathrm{NMR}\left(400 \mathrm{MHz}, \mathrm{CDCl}_{3}\right) \delta 1.25\left(\mathrm{~d}, 3 \mathrm{H}, \mathrm{CH}_{3}\right.$, $J=6.5 \mathrm{~Hz}), 1.26\left(\mathrm{~d}, 3 \mathrm{H}, \mathrm{CH}_{3}, J=6.5 \mathrm{~Hz}\right), 1.81\left(\mathrm{~s}, 3 \mathrm{H}, \mathrm{CH}_{3} \mathrm{CO}\right), 2.09\left(\mathrm{~s}, 3 \mathrm{H}, \mathrm{CH}_{3} \mathrm{CO}\right), 2.14\left(\mathrm{~s}, 3 \mathrm{H}, \mathrm{CH}_{3} \mathrm{CO}\right)$, $4.21(\mathrm{~m}, 1 \mathrm{H}, \mathrm{CH}), 4.26\left(\mathrm{dd}, 1 \mathrm{H}, \mathrm{H}-5^{\prime}, J_{5^{\prime}} .4^{\prime}=5.2 \mathrm{~Hz}, J_{5^{\prime}, 5^{\prime}}=12.5 \mathrm{~Hz}\right), 4.32\left(\mathrm{dd}, 1 \mathrm{H}, \mathrm{H}-5^{\prime}, J_{5^{\prime}}, 4^{\prime}=3.3 \mathrm{~Hz}\right.$, $\left.J_{5^{\prime}, 5^{\prime}}=12.3 \mathrm{~Hz}\right), 4.65\left(\mathrm{~m}, 1 \mathrm{H}, \mathrm{H}-4^{\prime}\right), 5.16\left(\mathrm{~d}, 1 \mathrm{H}, \mathrm{D}_{2} \mathrm{O}\right.$ exchangeable, $\left.\mathrm{NH}, J=7.0 \mathrm{~Hz}\right), 5.42\left(\mathrm{t}, 1 \mathrm{H}, \mathrm{H}-3^{\prime}\right.$, $J=5.4 \mathrm{~Hz}), 5.74\left(\mathrm{t}, 1 \mathrm{H}, \mathrm{H}-2^{\prime}, J=5.0 \mathrm{~Hz}\right), 6.23\left(\mathrm{~d}, 1 \mathrm{H}, \mathrm{H}-1^{\prime}, J_{1^{\prime}, 2^{\prime}}=4.7 \mathrm{~Hz}\right), 7.55(\mathrm{~s}, 1 \mathrm{H}, \mathrm{H}-7) .{ }^{13} \mathrm{C}-\mathrm{NMR}$ $\left(151 \mathrm{MHz}, \mathrm{CDCl}_{3}\right) \delta 20.26\left(\mathrm{CH}_{3} \mathrm{CO}\right), 20.53\left(\mathrm{CH}_{3} \mathrm{CO}\right), 20.88\left(\mathrm{CH}_{3} \mathrm{CO}\right), 22.67\left(\mathrm{CH}_{3}\right), 23.00\left(\mathrm{CH}_{3}\right), 45.87$ $(\mathrm{CH}), 63.29\left(\mathrm{C}-5^{\prime}\right), 70.98\left(\mathrm{C}-3^{\prime}\right), 71.48\left(\mathrm{C}-2^{\prime}\right), 78.84\left(\mathrm{C}-4^{\prime}\right), 85.35\left(\mathrm{C}-1^{\prime}\right), 119.32(\mathrm{C}-7), 119.43(\mathrm{C}-6), 125.58$ 
(C-7a), 140.92 (C-5), 154.52 (C-3a), 156.45 (C-2), 169.20 (CO), 169.55 (CO), 170.49 (CO). HR-MS (ESI) m/z: Calcd for $\mathrm{C}_{20} \mathrm{H}_{24} \mathrm{Cl}_{2} \mathrm{~N}_{4} \mathrm{O}_{7} \mathrm{Na}$ : $[\mathrm{M}+\mathrm{Na}]^{+}=525.0914$, found 525.0917 .

$N$-Benzyl-5,6-dichloro-3-(2', $3^{\prime}, 5^{\prime}$-tri-O-acetyl- $\beta$-D-ribofuranosyl)-3H-imidazo[4,5-b]pyridin-2-amine (8c), $N$-benzyl-5,6-dichloro-3-(2' $3^{\prime}, 5^{\prime}$-tri- $O$-acetyl- $\alpha$-D-ribofuranosyl)-3H-imidazo[4,5-b]pyridin-2-amine (9c), $N$-benzyl-5,6-dichloro-1-( $2^{\prime}, 3^{\prime}, 5^{\prime}$-tri-O-acetyl- $\beta$-D-ribofuranosyl)- $1 H$-imidazo[4,5-b]pyridin-2-amine (10c) and $N$-benzyl-5,6-dichloro-1-(2', $3^{\prime}, 5^{\prime}$-tri-O-acetyl- $\alpha$-D-ribofuranosyl)- $1 H$-imidazo[4,5-b]pyridin-2 -amine (11c): These derivatives were prepared by a procedure analogous to that described for 8a,9a,10a,11a, starting from imidazopyridine $7 \mathrm{c}(350 \mathrm{mg}, 1.20 \mathrm{mmol})$. Purification was effected by column chromatography, using a mixture of cyclohexane/EtOAc $(70 / 30$ to 20/80, $v / v)$ as the eluent, to afford 8c, as a mixture with its corresponding $\alpha$-anomer 9c (350 $\mathrm{mg}$, 53\% total yield for two anomers, 8c:9c (3- $\beta: \alpha)$ ratio 12:1, as estimated by $\left.{ }^{1} \mathrm{H}-\mathrm{NMR}\right), 10 \mathrm{c}(100 \mathrm{mg}$, crude) and $11 \mathrm{c}(40 \mathrm{mg}, 6 \%$ yield). Fractions containing 10c were pooled and subjected to column chromatography eluted with $\mathrm{CHCl}_{3} / \mathrm{MeOH}(99.5 / 0.5, v / v)$, yielding $80 \mathrm{mg}$ of pure $10 \mathrm{c}$ (12\% yield).

Data for 10c: Oil, $[\alpha]_{\mathrm{D}}+46.29\left(\mathrm{c}=0.337, \mathrm{CHCl}_{3}\right) .{ }^{1} \mathrm{H}$ NMR $\left(600 \mathrm{MHz}, \mathrm{CDCl}_{3}\right) \delta 1.91(\mathrm{~s}, 3 \mathrm{H}$, $\left.\mathrm{CH}_{3} \mathrm{CO}\right), 1.99$ (s, 3H, $\left.\mathrm{CH}_{3} \mathrm{CO}\right), 2.15\left(\mathrm{~s}, 3 \mathrm{H}, \mathrm{CH}_{3} \mathrm{CO}\right), 4.21\left(\mathrm{dd}, 1 \mathrm{H}, \mathrm{H}-5^{\prime}, J_{5^{\prime}, 4^{\prime}}=2.0 \mathrm{~Hz}, J_{5^{\prime}, 5^{\prime}}=12.6 \mathrm{~Hz}\right)$, $4.37\left(\mathrm{~m}, 1 \mathrm{H}, \mathrm{H}-4^{\prime}\right), 4.57\left(\mathrm{dd}, 1 \mathrm{H}, \mathrm{H}-5^{\prime}, J_{5^{\prime}, 4^{\prime}}=3.4 \mathrm{~Hz}, J_{5^{\prime}, 5^{\prime}}=12.6 \mathrm{~Hz}\right), 4.72\left(\mathrm{dd}, 1 \mathrm{H}, \mathrm{CH}_{2}, J_{\mathrm{CH} 2, \mathrm{NH}}=5.2\right.$ $\left.\mathrm{Hz}, J_{\mathrm{CH} 2, \mathrm{CH} 2}=14.8 \mathrm{~Hz}\right), 4.82\left(\mathrm{dd}, 1 \mathrm{H}, \mathrm{CH}_{2}, J_{\mathrm{CH} 2, \mathrm{NH}}=5.9 \mathrm{~Hz}, J_{\mathrm{CH} 2, \mathrm{CH} 2}=14.8 \mathrm{~Hz}\right), 5.30\left(\mathrm{dd}, 1 \mathrm{H}, \mathrm{H}-3^{\prime}\right.$, $\left.J_{3^{\prime}, 4^{\prime}}=3.1 \mathrm{~Hz}, J_{3^{\prime}, 2^{\prime}}=6.1 \mathrm{~Hz}\right), 5.37\left(\mathrm{~m}, 1 \mathrm{H}, \mathrm{H}-2^{\prime}\right), 5.87\left(\mathrm{~d}, 1 \mathrm{H}, \mathrm{H}-1^{\prime}, J_{1^{\prime}, 2^{\prime}}=7.6 \mathrm{~Hz}\right), 5.88\left(\mathrm{br} \mathrm{s}, 1 \mathrm{H}, \mathrm{D}_{2} \mathrm{O}\right.$ exchangeable, $\mathrm{NH}), 7.27\left(\mathrm{~m}, 1 \mathrm{H}\right.$, phenyl $\left.\mathrm{H}-4^{\prime \prime}\right), 7.32\left(\mathrm{t}, 2 \mathrm{H}\right.$, phenyl $\left.\mathrm{H}-3^{\prime \prime}, \mathrm{H}-5^{\prime \prime}, J=7.5 \mathrm{~Hz}\right), 7.37(\mathrm{~d}$,

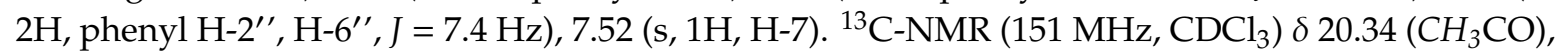
$20.52\left(\mathrm{CH}_{3} \mathrm{CO}\right), 20.70\left(\mathrm{CH}_{3} \mathrm{CO}\right), 47.62\left(\mathrm{CH}_{2}\right), 62.91\left(\mathrm{C}-5^{\prime}\right), 69.83\left(\mathrm{C}-3^{\prime}\right), 71.64\left(\mathrm{C}-2^{\prime}\right), 81.41\left(\mathrm{C}-4^{\prime}\right), 86.04$ $\left(\mathrm{C}-1^{\prime}\right), 117.40$ (C-7), 120.01 (C-6), 126.03 (C-7a), 127.89 (phenyl C-2' $\left.{ }^{\prime}, \mathrm{C}-6^{\prime \prime}\right), 128.01$ (phenyl C-4' $\left.{ }^{\prime \prime}\right), 128.96$ (phenyl C-3"', C-5'), 137.97 (phenyl C-1' $), 141.60$ (C-5), 154.26 (C-3a), 156.81 (C-2), 169.27 (CO), 169.71 (CO), 170.16 (CO). HR-MS (ESI) $m / z$ : Calcd for $\mathrm{C}_{24} \mathrm{H}_{24} \mathrm{Cl}_{2} \mathrm{~N}_{4} \mathrm{O}_{7} \mathrm{Na}$ : $[\mathrm{M}+\mathrm{Na}]^{+}=573.0914$, found 573.0919 .

Data for 11c: Oil, $[\alpha]_{\mathrm{D}}+53.17\left(c=0.600, \mathrm{CHCl}_{3}\right) .{ }^{1} \mathrm{H}$ NMR $\left(600 \mathrm{MHz}, \mathrm{CDCl}_{3}\right) \delta 1.72(\mathrm{~s}, 3 \mathrm{H}$, $\left.\mathrm{CH}_{3} \mathrm{CO}\right), 2.00\left(\mathrm{~s}, 3 \mathrm{H}, \mathrm{CH}_{3} \mathrm{CO}\right), 2.12\left(\mathrm{~s}, 3 \mathrm{H}, \mathrm{CH}_{3} \mathrm{CO}\right), 4.27\left(\mathrm{dd}, 1 \mathrm{H}, \mathrm{H}-5^{\prime}, J_{5^{\prime}, 4^{\prime}}=4.8 \mathrm{~Hz}, J_{5^{\prime}, 5^{\prime}}=12.4 \mathrm{~Hz}\right)$, $4.30\left(\mathrm{dd}, 1 \mathrm{H}, \mathrm{H}-5^{\prime}, J_{5^{\prime}, 4^{\prime}}=3.5 \mathrm{~Hz}, J_{5^{\prime}, 5^{\prime}}=12.3 \mathrm{~Hz}\right), 4.62\left(\mathrm{~m}, 1 \mathrm{H}, \mathrm{H}-4^{\prime}\right), 4.69\left(\mathrm{dd}, 1 \mathrm{H}, \mathrm{CH}_{2}, J_{\mathrm{CH} 2, \mathrm{NH}}=5.0\right.$ $\left.\mathrm{Hz}, J_{\mathrm{CH} 2, \mathrm{CH} 2}=14.5 \mathrm{~Hz}\right), 4.76\left(\mathrm{dd}, 1 \mathrm{H}, \mathrm{CH}_{2}, J_{\mathrm{CH} 2, \mathrm{NH}}=5.5 \mathrm{~Hz}, J_{\mathrm{CH} 2, \mathrm{CH} 2}=14.5 \mathrm{~Hz}\right), 5.44\left(\mathrm{t}, 1 \mathrm{H}, \mathrm{H}-3^{\prime}\right.$, $J=5.2 \mathrm{~Hz}), 5.60\left(\mathrm{br} \mathrm{s}, 1 \mathrm{H}, \mathrm{D}_{2} \mathrm{O}\right.$ exchangeable, $\left.\mathrm{NH}\right), 5.71\left(\mathrm{t}, 1 \mathrm{H}, \mathrm{H}-2^{\prime}, J=5.2 \mathrm{~Hz}\right), 6.19\left(\mathrm{~d}, 1 \mathrm{H}, \mathrm{H}-\mathrm{1}^{\prime}\right.$,

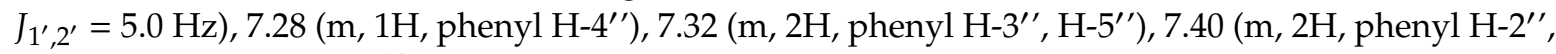
$\left.\mathrm{H}-6^{\prime \prime}\right), 7.53(\mathrm{~s}, 1 \mathrm{H}, \mathrm{H}-7) .{ }^{13} \mathrm{C}-\mathrm{NMR}\left(151 \mathrm{MHz}, \mathrm{CDCl}_{3}\right) \delta 20.08\left(\mathrm{CH}_{3} \mathrm{CO}\right), 20.40\left(\mathrm{CH}_{3} \mathrm{CO}\right), 20.94\left(\mathrm{CH}_{3} \mathrm{CO}\right)$, $47.73\left(\mathrm{CH}_{2}\right), 63.24\left(\mathrm{C}-5^{\prime}\right), 71.03\left(\mathrm{C}-3^{\prime}\right), 71.39\left(\mathrm{C}-2^{\prime}\right), 79.20\left(\mathrm{C}-4^{\prime}\right), 85.46\left(\mathrm{C}-1^{\prime}\right), 118.91(\mathrm{C}-7), 119.87(\mathrm{C}-6)$,

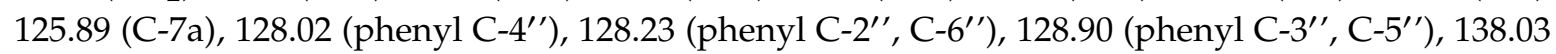
(phenyl C-1' '), 141.44 (C-5), 154.31 (C-3a), 157.13 (C-2), 169.33 (CO), 169.53 (CO), 170.39 (CO). HR-MS (ESI) $m / z$ : Calcd for $\mathrm{C}_{24} \mathrm{H}_{24} \mathrm{Cl}_{2} \mathrm{~N}_{4} \mathrm{O}_{7} \mathrm{Na}:[\mathrm{M}+\mathrm{Na}]^{+}=573.0914$, found 573.0920.

5,6-Dichloro- $N, 1$-bis-( $2^{\prime}, 3^{\prime}, 5^{\prime}$-tri-O-acetyl- $\beta$-D-ribofuranosyl)-1H-imidazo[4,5-b]pyridin-2-amine (14), 5,6-dichloro-3-(2' $3^{\prime}, 5^{\prime}$-tri-O-acetyl- $\beta$-D-ribofuranosyl)-3H-imidazo[4,5-b]pyridin-2-amine (8d) and 5,6-dichloro-1-( $2^{\prime}, 3^{\prime}, 5^{\prime}$-tri-O-acetyl- $\beta$-D-ribofuranosyl)-1H-imidazo[4,5-b]pyridin-2-amine (10d): These derivatives were prepared by a procedure analogous to that described for $\mathbf{8 a}$ and $\mathbf{1 0 a}$, starting from $7 \mathbf{d}(245 \mathrm{mg}, 1.21 \mathrm{mmol})$. Purification was effected by column chromatography, using a mixture of $\mathrm{CHCl}_{3} / \mathrm{MeOH}$ (99.5/0.5 to 95.5/4.5, v/v) as the eluent, to afford $\mathbf{1 4}$ (300 mg, 35\% yield), 8d (150 mg, 27\% yield) and $10 \mathrm{~d}(40 \mathrm{mg}, 7 \%$ yield).

Data for 14: Oil, $[\alpha]_{\mathrm{D}}-25.60\left(c=0.703, \mathrm{CHCl}_{3}\right) .{ }^{1} \mathrm{H}$ NMR $\left(600 \mathrm{MHz}, \mathrm{CDCl}_{3}\right) \delta 2.07\left(\mathrm{~s}, 3 \mathrm{H}, \mathrm{CH}_{3} \mathrm{CO}\right)$, 2.07 (s, 3H, $\left.\mathrm{CH}_{3} \mathrm{CO}\right), 2.11$ (s, 3H, $\left.\mathrm{CH}_{3} \mathrm{CO}\right), 2.13$ (s, 3H, $\left.\mathrm{CH}_{3} \mathrm{CO}\right), 2.14\left(\mathrm{~s}, 3 \mathrm{H}, \mathrm{CH}_{3} \mathrm{CO}\right), 2.23(\mathrm{~s}, 3 \mathrm{H}$, $\left.\mathrm{CH}_{3} \mathrm{CO}\right), 4.30-4.33\left(\mathrm{~m}, 3 \mathrm{H}, 2 \times \mathrm{H}-4^{\prime}, 1 \times \mathrm{H}-5^{\prime}\right), 4.36\left(\mathrm{dd}, 1 \mathrm{H}, \mathrm{H}-5^{\prime}, J_{5^{\prime}, 4^{\prime}}=5.1 \mathrm{~Hz}, J_{5^{\prime}, 5^{\prime}}=12.1 \mathrm{~Hz}\right), 4.42$ $\left(\mathrm{dd}, 1 \mathrm{H}, \mathrm{H}-5^{\prime}, J_{5^{\prime}, 4^{\prime}}=3.4 \mathrm{~Hz}, J_{5^{\prime}, 5^{\prime}}=12.1 \mathrm{~Hz}\right), 4.50\left(\mathrm{~m}, 1 \mathrm{H}, \mathrm{H}-5^{\prime}\right), 5.44\left(\mathrm{dd}, 1 \mathrm{H}, \mathrm{H}-3^{\prime}, J_{3^{\prime}, 4^{\prime}}=3.6 \mathrm{~Hz}\right.$, $J_{3^{\prime}, 2^{\prime}}=6.2 \mathrm{~Hz}$ ), 5.56 (br s, $\left.1 \mathrm{H}, \mathrm{H}-2^{\prime}\right), 5.71$ (br s, $\left.1 \mathrm{H}, \mathrm{H}-3^{\prime}\right), 5.97$ (br s, $\left.1 \mathrm{H}, \mathrm{H}-1^{\prime}\right), 6.03$ (br s, $\left.1 \mathrm{H}, \mathrm{H}-2^{\prime}\right), 6.07$ (br s, $\left.1 \mathrm{H}, \mathrm{H}-\mathrm{1}^{\prime}\right), 7.39$ (s,1H, H-7). ${ }^{13} \mathrm{C}-\mathrm{NMR}\left(151 \mathrm{MHz}, \mathrm{CDCl}_{3}\right) \delta 20.50\left(\mathrm{CH}_{3} \mathrm{CO}\right), 20.60\left(\mathrm{CH}_{3} \mathrm{CO}\right), 20.68$ ( $\left.\mathrm{CH}_{3} \mathrm{CO}\right), 20.69\left(\mathrm{CH}_{3} \mathrm{CO}\right), 20.90\left(\mathrm{CH}_{3} \mathrm{CO}\right), 21.06\left(\mathrm{CH}_{3} \mathrm{CO}\right), 63.35\left(2 \times \mathrm{C}-5^{\prime}\right), 70.04,70.10,70.49,70.77(2 \times$ 
C-2', $2 \times$ C-3'), $79.73\left(\mathrm{C}-4^{\prime}\right), 80.33\left(\mathrm{C}-4^{\prime}\right), 85.06\left(\mathrm{C}-1^{\prime}\right), 85.13\left(\mathrm{C}-1^{\prime}\right), 117.37$ (C-7), 122.62, 123.67 (C-6 and C-7a), 139.26, 142.47 (C-3a, C-5), 149.92 (C-2), 169.67 (3 ×CO), 169.76 (CO), 170.37 (CO), 170.65 (CO). HR-MS (ESI) $m / z$ : Calcd for $\mathrm{C}_{28} \mathrm{H}_{32} \mathrm{Cl}_{2} \mathrm{~N}_{4} \mathrm{O}_{14} \mathrm{Na}$ : $[\mathrm{M}+\mathrm{Na}]^{+}=741.1184$, found 741.1185.

Data for 8d: Oil, $[\alpha]_{\mathrm{D}}+52.57\left(c=0.675, \mathrm{CHCl}_{3}\right) .{ }^{1} \mathrm{H} \mathrm{NMR}\left(600 \mathrm{MHz}, \mathrm{CDCl}_{3}\right) \delta 2.03\left(\mathrm{~s}, 3 \mathrm{H}, \mathrm{CH}_{3} \mathrm{CO}\right)$, $2.11\left(\mathrm{~s}, 3 \mathrm{H}, \mathrm{CH}_{3} \mathrm{CO}\right), 2.16\left(\mathrm{~s}, 3 \mathrm{H}, \mathrm{CH}_{3} \mathrm{CO}\right), 4.35\left(\mathrm{dd}, 1 \mathrm{H}, \mathrm{H}-5^{\prime}, J_{5^{\prime}, 4^{\prime}}=2.7 \mathrm{~Hz}, J_{5^{\prime}, 5^{\prime}}=12.2 \mathrm{~Hz}\right), 4.38$ $\left(\mathrm{m}, 1 \mathrm{H}, \mathrm{H}-4^{\prime}\right), 4.59\left(\mathrm{dd}, 1 \mathrm{H}, \mathrm{H}-5^{\prime}, J_{5^{\prime}, 4^{\prime}}=4.0 \mathrm{~Hz}, J_{5^{\prime}, 5^{\prime}}=12.2 \mathrm{~Hz}\right), 5.50\left(\mathrm{dd}, 1 \mathrm{H}, \mathrm{H}-3^{\prime}, J_{3^{\prime}, 4^{\prime}}=4.3 \mathrm{~Hz}\right.$, $\left.J_{3^{\prime}, 2^{\prime}}=6.2 \mathrm{~Hz}\right), 5.75\left(\mathrm{~m}, 1 \mathrm{H}, \mathrm{H}-2^{\prime}\right), 5.87\left(\mathrm{br} \mathrm{s}, 2 \mathrm{H}, \mathrm{D}_{2} \mathrm{O}\right.$ exchangeable, $\left.\mathrm{NH}_{2}\right), 6.23\left(\mathrm{~d}, 1 \mathrm{H}, \mathrm{H}-1^{\prime}, J_{1^{\prime}, 2^{\prime}}=6.5\right.$ $\mathrm{Hz}), 7.63(\mathrm{~s}, 1 \mathrm{H}, \mathrm{H}-7) .{ }^{13} \mathrm{C}-\mathrm{NMR}\left(151 \mathrm{MHz}, \mathrm{CDCl}_{3}\right) \delta 20.48\left(\mathrm{CH}_{3} \mathrm{CO}\right), 20.70\left(\mathrm{CH}_{3} \mathrm{CO}\right), 20.83\left(\mathrm{CH}_{3} \mathrm{CO}\right)$, $63.24\left(\mathrm{C}-5^{\prime}\right), 70.27\left(\mathrm{C}-3^{\prime}\right), 71.19\left(\mathrm{C}-2^{\prime}\right), 80.73\left(\mathrm{C}-4^{\prime}\right), 85.04\left(\mathrm{C}-1^{\prime}\right), 123.94$ (C-6), 125.17 (C-7), 135.02, 138.38 (C-5 and C-7a), 144.67 (C-3a), 155.30 (C-2), 169.85 (CO), 169.86 (CO), 170.24 (CO). HR-MS (ESI) m/z: Calcd for $\mathrm{C}_{17} \mathrm{H}_{18} \mathrm{Cl}_{2} \mathrm{~N}_{4} \mathrm{O}_{7} \mathrm{Na}$ : $[\mathrm{M}+\mathrm{Na}]^{+}=483.0445$, found 483.0449 .

Data for 10d: Oil, $[\alpha]_{\mathrm{D}}+22.70\left(c=0.185, \mathrm{CHCl}_{3}\right) .{ }^{1} \mathrm{H}$ NMR $\left(600 \mathrm{MHz}, \mathrm{CDCl}_{3}\right) \delta 2.02(\mathrm{~s}, 3 \mathrm{H}$, $\left.\mathrm{CH}_{3} \mathrm{CO}\right), 2.16\left(\mathrm{~s}, 3 \mathrm{H}, \mathrm{CH}_{3} \mathrm{CO}\right), 2.35\left(\mathrm{~s}, 3 \mathrm{H}, \mathrm{CH}_{3} \mathrm{CO}\right), 4.31\left(\mathrm{dd}, 1 \mathrm{H}, \mathrm{H}-5^{\prime}, J_{5^{\prime}, 4^{\prime}}=2.1 \mathrm{~Hz}, J_{5^{\prime}, 5^{\prime}}=12.5 \mathrm{~Hz}\right)$, $4.43\left(\mathrm{~m}, 1 \mathrm{H}, \mathrm{H}-4^{\prime}\right), 4.65\left(\mathrm{dd}, 1 \mathrm{H}, \mathrm{H}-5^{\prime}, J_{5^{\prime}, 4^{\prime}}=1.9 \mathrm{~Hz}, J_{5^{\prime}, 5^{\prime}}=12.5 \mathrm{~Hz}\right), 5.39\left(\mathrm{dd}, 1 \mathrm{H}, \mathrm{H}-3^{\prime}, J_{3^{\prime}, 4^{\prime}}=3.2 \mathrm{~Hz}\right.$, $\left.J_{3^{\prime}, 2^{\prime}}=6.2 \mathrm{~Hz}\right), 5.47\left(\mathrm{~m}, 1 \mathrm{H}, \mathrm{H}-2^{\prime}\right), 5.89\left(\mathrm{~d}, 1 \mathrm{H}, \mathrm{H}-1^{\prime}, J_{1^{\prime}, 2^{\prime}}=7.5 \mathrm{~Hz}\right), 7.47$ (br s, $2 \mathrm{H}, \mathrm{D}_{2} \mathrm{O}$ exchangeable, $\left.\mathrm{NH}_{2}\right), 7.52(\mathrm{~s}, 1 \mathrm{H}, \mathrm{H}-7) .{ }^{13} \mathrm{C}-\mathrm{NMR}\left(151 \mathrm{MHz}, \mathrm{CDCl}_{3}\right) \delta 20.36\left(\mathrm{CH}_{3} \mathrm{CO}\right), 20.65\left(\mathrm{CH}_{3} \mathrm{CO}\right), 21.23\left(\mathrm{CH}_{3} \mathrm{CO}\right)$, $63.01\left(\mathrm{C}-5^{\prime}\right), 70.07\left(\mathrm{C}-3^{\prime}\right), 71.20\left(\mathrm{C}-2^{\prime}\right), 81.20\left(\mathrm{C}-4^{\prime}\right), 86.11\left(\mathrm{C}-1^{\prime}\right), 117.54$ (C-7), 119.80 (C-6), 125.35 (C-7a), 141.36 (C-5), 153.77 (C-3a), 157.58 (C-2), 169.30 (CO), 169.71 (CO), 170.43 (CO). HR-MS (ESI) m/z: Calcd for $\mathrm{C}_{17} \mathrm{H}_{18} \mathrm{Cl}_{2} \mathrm{~N}_{4} \mathrm{O}_{7} \mathrm{Na}:[\mathrm{M}+\mathrm{Na}]^{+}=483.0445$, found 483.0440.

5,6-Dichloro- $N$-ethyl-3-( $\beta$-D-ribofuranosyl)-3H-imidazo[4,5-b]pyridin-2-amine (12a): A mixture of 8a and $9 \mathrm{a}(80 \mathrm{mg}, 0.16 \mathrm{mmol})$ was treated for $18 \mathrm{~h}$ with a saturated methanolic ammonia solution (15 $\mathrm{mL}$ ). Upon evaporation of the solvent, the residue was purified by column chromatography using a mixture of EtOAc/MeOH: 99/1 (v/v), as the eluent and the desired product was recrystallized from methanol to provide pure 12a (35 mg, 59\% yield). White solid, mp: $191-192{ }^{\circ} \mathrm{C}(\mathrm{MeOH}) \cdot[\alpha]_{\mathrm{D}}+31.88$ $(c=0.367, \mathrm{MeOH}) .{ }^{1} \mathrm{H}$ NMR $\left(600 \mathrm{MHz}, \mathrm{DMSO}-d_{6}\right) \delta 1.19\left(\mathrm{t}, 3 \mathrm{H}, \mathrm{CH}_{3}, J=7.2 \mathrm{~Hz}\right), 3.41\left(\mathrm{~m}, 2 \mathrm{H}, \mathrm{CH}_{2}\right.$, overlapping with water of DMSO- $\left.d_{6}\right), 3.66\left(\mathrm{~m}, 2 \mathrm{H}, \mathrm{H}-5^{\prime}\right), 3.99\left(\mathrm{~m}, 1 \mathrm{H}, \mathrm{H}-4^{\prime}\right), 4.12\left(\mathrm{dd}, 1 \mathrm{H}, \mathrm{H}-3^{\prime}\right.$, $\left.J_{3^{\prime}, 4^{\prime}}=1.5 \mathrm{~Hz}, J_{3^{\prime}, 2^{\prime}}=5.2 \mathrm{~Hz}\right), 4.59\left(\mathrm{dd}, 1 \mathrm{H}, \mathrm{H}-2^{\prime}, J_{2^{\prime}, 3^{\prime}}=5.2 \mathrm{~Hz}, J_{2^{\prime}, 1^{\prime}}=7.3 \mathrm{~Hz}\right), 5.05-5.55\left(\mathrm{br} \mathrm{s}, 2 \mathrm{H}, \mathrm{D}_{2} \mathrm{O}\right.$ exchangeable, $2 \times \mathrm{OH}), 5.75\left(\mathrm{br} \mathrm{s}, 1 \mathrm{H}, \mathrm{D}_{2} \mathrm{O}\right.$ exchangeable, $\left.\mathrm{OH}\right), 5.96\left(\mathrm{~d}, 1 \mathrm{H}, \mathrm{H}-1^{\prime}, J_{1^{\prime}, 2^{\prime}}=7.5 \mathrm{~Hz}\right), 7.64$ (br s, $1 \mathrm{H}, \mathrm{D}_{2} \mathrm{O}$ exchangeable, $\left.\mathrm{NH}\right), 7.78(\mathrm{~s}, 1 \mathrm{H}, \mathrm{H}-7) .{ }^{13} \mathrm{C}-\mathrm{NMR}\left(151 \mathrm{MHz}, \mathrm{DMSO}-d_{6}\right) \delta 14.50\left(\mathrm{CH}_{3}\right)$, $37.08\left(\mathrm{CH}_{2}\right), 61.42\left(\mathrm{C}-5^{\prime}\right), 70.29\left(\mathrm{C}-2^{\prime}\right), 71.04\left(\mathrm{C}-3^{\prime}\right), 85.74\left(\mathrm{C}-4^{\prime}\right), 86.37\left(\mathrm{C}-1^{\prime}\right), 121.03(\mathrm{C}-6), 122.82(\mathrm{C}-7)$, 134.65, 136.07 (C-5 and C-7a), 145.96 (C-3a), 155.48 (C-2). HR-MS (ESI) $m / z$ : Calcd for $\mathrm{C}_{13} \mathrm{H}_{17} \mathrm{Cl}_{2} \mathrm{~N}_{4} \mathrm{O}_{4}$ : $[\mathrm{M}+\mathrm{H}]^{+}=363.0621$, found 363.0615 .

5,6-Dichloro- $N$-isopropyl-3-( $\beta$-D-ribofuranosyl)-3H-imidazo[4,5-b]pyridin-2-amine (12b): This compound was prepared by a procedure analogous to that described for 12a starting from $\mathbf{8 b}$ (90 $\mathrm{mg}, 0.18 \mathrm{mmol}$, containing also the corresponding $\alpha$-anomer $9 \mathbf{b}$ ). Purification was effected by column chromatography using a mixture of DCM/MeOH: 98/2 to 95/5 (v/v) as the eluent, to afford $\mathbf{1 2 b}$ (55 mg, $81 \%$ yield). White solid, mp: $127-128^{\circ} \mathrm{C}$ (EtOAc/n-pentane). $[\alpha]_{\mathrm{D}}+30.77(c=0.494, \mathrm{MeOH}) .{ }^{1} \mathrm{H}$ NMR $\left(600 \mathrm{MHz}, \mathrm{DMSO}-d_{6}\right) \delta 1.21\left(\mathrm{~d}, 3 \mathrm{H}, \mathrm{CH}_{3}, J=6.5 \mathrm{~Hz}\right), 1.22\left(\mathrm{~d}, 3 \mathrm{H}, \mathrm{CH}_{3}, J=6.5 \mathrm{~Hz}\right), 3.65\left(\mathrm{dd}, 1 \mathrm{H}, \mathrm{H}-5^{\prime}\right.$, $\left.J_{5^{\prime}, 4^{\prime}}=2.8 \mathrm{~Hz}, J_{5^{\prime}, 5^{\prime}}=11.7 \mathrm{~Hz}\right), 3.68\left(\mathrm{dd}, 1 \mathrm{H}, \mathrm{H}-5^{\prime}, J_{5^{\prime}, 4^{\prime}}=2.0 \mathrm{~Hz}, J_{5^{\prime}, 5^{\prime}}=11.7 \mathrm{~Hz}\right), 3.99\left(\mathrm{~m}, 1 \mathrm{H}, \mathrm{H}-4^{\prime}\right)$, $4.11-4.18\left(\mathrm{~m}, 2 \mathrm{H}, \mathrm{H}-3^{\prime}, \mathrm{CH}\right), 4.56\left(\mathrm{dd}, 1 \mathrm{H}, \mathrm{H}-2^{\prime}, J_{2^{\prime}, 3^{\prime}}=5.4 \mathrm{~Hz}, \mathrm{~J}_{2^{\prime}, 1^{\prime}}=7.6 \mathrm{~Hz}\right), 5.02-5.52\left(\mathrm{br} \mathrm{s}, 2 \mathrm{H}, \mathrm{D}_{2} \mathrm{O}\right.$ exchangeable, $2 \times \mathrm{OH}), 5.72\left(\mathrm{br} \mathrm{s}, 1 \mathrm{H}, \mathrm{D}_{2} \mathrm{O}\right.$ exchangeable, $\left.\mathrm{OH}\right), 5.97\left(\mathrm{~d}, 1 \mathrm{H}, \mathrm{H}-1^{\prime}, J_{1^{\prime}, 2^{\prime}}=7.6 \mathrm{~Hz}\right), 7.44$ $\left(\mathrm{d}, 1 \mathrm{H}, \mathrm{D}_{2} \mathrm{O}\right.$ exchangeable, $\left.\mathrm{NH}, J=7.5 \mathrm{~Hz}\right), 7.78(\mathrm{~s}, 1 \mathrm{H}, \mathrm{H}-7) .{ }^{13} \mathrm{C}-\mathrm{NMR}\left(151 \mathrm{MHz}, \mathrm{DMSO}-d_{6}\right) \delta 22.23$ $\left(\mathrm{CH}_{3}\right), 22.37\left(\mathrm{CH}_{3}\right), 44.36(\mathrm{CH}), 61.42\left(\mathrm{C}-5^{\prime}\right), 70.25\left(\mathrm{C}-2^{\prime}\right), 71.03\left(\mathrm{C}-3^{\prime}\right), 85.71\left(\mathrm{C}-4^{\prime}\right), 86.26\left(\mathrm{C}-1^{\prime}\right), 121.00$ (C-6), 122.72 (C-7), 134.60, 135.99 (C-5 and C-7a), 145.91 (C-3a), 154.84 (C-2). HR-MS (ESI) m/z: Calcd for $\mathrm{C}_{14} \mathrm{H}_{19} \mathrm{Cl}_{2} \mathrm{~N}_{4} \mathrm{O}_{4}:[\mathrm{M}+\mathrm{H}]^{+}=377.0778$, found 377.0786.

$\mathrm{N}$-Benzyl-5,6-dichloro-3-( $\beta$-D-ribofuranosyl)-3H-imidazo[4,5-b]pyridin-2-amine (12c): This compound was prepared by a procedure analogous to that described for 12a starting from $\mathbf{8 c}(130$ $\mathrm{mg}, 0.23 \mathrm{mmol}$, containing also the corresponding $\alpha$-anomer $9 \mathrm{c}$ ). Purification was effected by column chromatography using a mixture of DCM/MeOH: 98/2 to 90/10 (v/v) to afford an anomeric mixture $\beta / \alpha$, in a 12/1 ratio $(80 \mathrm{mg})$. A second column chromatography was performed (DCM/MeOH: 97.5/2.5 
to $90 / 10, v / v)$ and the fractions pooled $(30 \mathrm{mg})$ were enriched in the desired $\beta$-anomer $12 \mathrm{c}(\beta / \alpha$ ratio: 17/1). From this mixture, pure 12c (12 mg) was obtained by semi-preparative HPLC, eluted with $\mathrm{H}_{2} \mathrm{O}$ $(+0.2 \%$ Acetic Acid $) / \mathrm{ACN}(70 / 30$ to $60 / 40, v / v$, over a period of $40 \mathrm{~min}) ; \mathrm{t}_{\mathrm{R}}=23.96 \mathrm{~min}$. Oil, $[\alpha]_{\mathrm{D}}+6.44$ $(c=0.652, \mathrm{MeOH}) .{ }^{1} \mathrm{H}$ NMR (600 MHz, DMSO-d6) $\delta 3.67$ (br s, 2H, H-5'), $4.02\left(\mathrm{~m}, 1 \mathrm{H}, \mathrm{H}-4^{\prime}\right), 4.14(\mathrm{~m}$, $\left.1 \mathrm{H}, \mathrm{H}-3^{\prime}\right), 4.58\left(\mathrm{dd}, 1 \mathrm{H}, \mathrm{CH}_{2}, J_{\mathrm{CH} 2, \mathrm{NH}}=5.8 \mathrm{~Hz}, J_{\mathrm{CH} 2, \mathrm{CH} 2}=15.6 \mathrm{~Hz}\right), 4.63\left(\mathrm{dd}, 1 \mathrm{H}, \mathrm{CH}_{2}, J_{\mathrm{CH} 2, \mathrm{NH}}=6.4\right.$ $\left.\mathrm{Hz}, J_{\mathrm{CH} 2, \mathrm{CH} 2}=15.6 \mathrm{~Hz}\right), 4.67\left(\mathrm{~m}, 1 \mathrm{H}, \mathrm{H}-2^{\prime}\right), 5.22\left(\mathrm{~d}, 1 \mathrm{H}, \mathrm{D}_{2} \mathrm{O}\right.$ exchangeable, $\left.\mathrm{OH}-3^{\prime}, J=4.1 \mathrm{~Hz}\right), 5.40(\mathrm{~d}$, $1 \mathrm{H}, \mathrm{D}_{2} \mathrm{O}$ exchangeable, $\left.\mathrm{OH}-2^{\prime}, J=6.3 \mathrm{~Hz}\right), 5.72\left(\mathrm{t}, 1 \mathrm{H}, \mathrm{D}_{2} \mathrm{O}\right.$ exchangeable, $\left.\mathrm{OH}-5^{\prime}, J=4.3 \mathrm{~Hz}\right), 6.01(\mathrm{~d}$, $\left.1 \mathrm{H}, \mathrm{H}-1^{\prime}, J_{1^{\prime}, 2^{\prime}}=7.5 \mathrm{~Hz}\right), 7.23\left(\mathrm{t}, 1 \mathrm{H}\right.$, phenyl H-4 $\left.{ }^{\prime \prime}, J=7.1 \mathrm{~Hz}\right), 7.32\left(\mathrm{t}, 2 \mathrm{H}\right.$, phenyl H- ${ }^{\prime \prime}{ }^{\prime}, \mathrm{H}-5^{\prime \prime}{ }^{\prime}, J=7.6$ $\mathrm{Hz}), 7.35\left(\mathrm{~d}, 2 \mathrm{H}\right.$, phenyl H-2" $\left.{ }^{\prime}, \mathrm{H}-6^{\prime \prime}, J=7.2 \mathrm{~Hz}\right), 7.78(\mathrm{~s}, 1 \mathrm{H}, \mathrm{H}-7), 8.25\left(\mathrm{t}, 1 \mathrm{H}, \mathrm{D}_{2} \mathrm{O}\right.$ exchangeable, $\mathrm{NH}$, $J=6.1 \mathrm{~Hz}) .{ }^{13} \mathrm{C}-\mathrm{NMR}\left(151 \mathrm{MHz}, \mathrm{DMSO}-d_{6}\right) \delta 45.14\left(\mathrm{CH}_{2}\right), 61.45\left(\mathrm{C}-5^{\prime}\right), 70.53\left(\mathrm{C}-2^{\prime}\right), 71.05\left(\mathrm{C}-3^{\prime}\right), 85.80$ (C-4'), 86.46 (C-1'), 121.08 (C-6), 123.09 (C-7), 126.79 (phenyl C-4'”), 126.99 (phenyl C-2'", C-6"'), 128.26 (phenyl C-3"', C-5'), 134.73, 136.10 (C-5 and C-7a), 139.25 (phenyl C-1'), 146.01 (C-3a), 155.69 (C-2). HR-MS (ESI) $m / z$ : Calcd for $\mathrm{C}_{18} \mathrm{H}_{17} \mathrm{Cl}_{2} \mathrm{~N}_{4} \mathrm{O}_{4}:[\mathrm{M}-\mathrm{H}]^{-}=423.0632$, found 423.0632.

5,6-Dichloro-3-( $\beta$-D-ribofuranosyl)-3H-imidazo[4,5-b]pyridin-2-amine (12d): This compound was prepared by a procedure analogous to that described for 12a, starting from $8 \mathbf{d}(100 \mathrm{mg}, 0.22 \mathrm{mmol})$. Purification was effected by column chromatography using a mixture of DCM/MeOH: 97/3 to 90/10 $(v / v)$ as the eluent, to result in $12 \mathrm{~d}\left(70 \mathrm{mg}, 96 \%\right.$ yield). Beige solid, $\mathrm{mp}: 142-143{ }^{\circ} \mathrm{C}$ (toluene). $[\alpha]_{\mathrm{D}}$ +16.50 ( $c=0.594, \mathrm{MeOH}) .{ }^{1} \mathrm{HNMR}\left(600 \mathrm{MHz}, \mathrm{DMSO}-d_{6}\right) \delta 3.64\left(\mathrm{brs}, 2 \mathrm{H}, \mathrm{H}-5^{\prime}\right), 3.98\left(\mathrm{~m}, 1 \mathrm{H}, \mathrm{H}-4^{\prime}\right)$, $4.12\left(\mathrm{~m}, 1 \mathrm{H}, \mathrm{H}-3^{\prime}\right), 4.62\left(\mathrm{~m}, 1 \mathrm{H}, \mathrm{H}-2^{\prime}\right), 5.20$ (br s, $1 \mathrm{H}, \mathrm{D}_{2} \mathrm{O}$ exchangeable, $\left.\mathrm{OH}-3^{\prime}\right), 5.35$ (brs, $1 \mathrm{H}, \mathrm{D}_{2} \mathrm{O}$ exchangeable, $\left.\mathrm{OH}-2^{\prime}\right), 5.58$ (brs, $1 \mathrm{H}, \mathrm{D}_{2} \mathrm{O}$ exchangeable, $\left.\mathrm{OH}-5^{\prime}\right), 5.94\left(\mathrm{~d}, 1 \mathrm{H}, \mathrm{H}-1^{\prime}, J_{1^{\prime}, 2^{\prime}}=7.4 \mathrm{~Hz}\right), 7.39$ (brs, $2 \mathrm{H}, \mathrm{D}_{2} \mathrm{O}$ exchangeable, $\left.\mathrm{NH}_{2}\right), 7.71(\mathrm{~s}, 1 \mathrm{H}, \mathrm{H}-7) .{ }^{13} \mathrm{C}-\mathrm{NMR}\left(151 \mathrm{MHz}, \mathrm{DMSO}-d_{6}\right) \delta 61.44\left(\mathrm{C}-5^{\prime}\right)$, 70.31 (C-2'), 70.95 (C-3'), $85.73\left(\mathrm{C}-4^{\prime}\right), 86.37$ (C-1'), 121.12 (C-6), 122.58 (C-7), 134.39, 136.37 (C-5 and C-7a), 145.71 (C-3a), 156.45 (C-2). HR-MS (ESI) $m / z$ : Calcd for $\mathrm{C}_{11} \mathrm{H}_{13} \mathrm{Cl}_{2} \mathrm{~N}_{4} \mathrm{O}_{4}$ : $[\mathrm{M}+\mathrm{H}]^{+}=335.0308$, found 335.0317 .

5,6-Dichloro- $N$-ethyl-1-( $\beta$-D-ribofuranosyl)- $1 H$-imidazo[4,5-b]pyridin-2-amine $\quad(13 a): \quad$ This compound was prepared by a procedure analogous to that described for 12a starting from 10a $(50 \mathrm{mg}$, $0.10 \mathrm{mmol}$ ). Purification was effected by column chromatography using a mixture of $\mathrm{DCM} / \mathrm{MeOH}$ : 98/2 to $85 / 15(v / v)$ as the eluent to afford 13a (30 mg, $81 \%$ yield). White solid, mp: $226-227^{\circ} \mathrm{C}(\mathrm{MeOH})$. $[\alpha]_{\mathrm{D}}+47.23(c=0.271, \mathrm{MeOH}) .{ }^{1} \mathrm{HNMR}\left(600 \mathrm{MHz}, \mathrm{DMSO}-d_{6}\right) \delta 1.18\left(\mathrm{t}, 3 \mathrm{H}, \mathrm{CH}_{3}, J=7.2 \mathrm{~Hz}\right), 3.41(\mathrm{~m}$, $2 \mathrm{H}, \mathrm{CH}_{2}$, overlapping with water of DMSO- $\left.d_{6}\right), 3.66\left(\mathrm{dd}, 1 \mathrm{H}, \mathrm{H}-5^{\prime}, J_{5^{\prime}, 4^{\prime}}=2.0 \mathrm{~Hz}, J_{5^{\prime}, 5^{\prime}}=11.8 \mathrm{~Hz}\right), 3.71$ $\left(\mathrm{m}, 1 \mathrm{H}, \mathrm{H}-5^{\prime}\right), 4.00\left(\mathrm{~m}, 1 \mathrm{H}, \mathrm{H}-4^{\prime}\right), 4.08\left(\mathrm{dd}, 1 \mathrm{H}, \mathrm{H}-3^{\prime}, J_{3^{\prime}, 4^{\prime}}=1.6 \mathrm{~Hz}, J_{3^{\prime}, 2^{\prime}}=5.5 \mathrm{~Hz}\right), 4.28\left(\mathrm{~m}, 1 \mathrm{H}, \mathrm{H}-2^{\prime}\right)$, 5.22-5.37 (brs, $2 \mathrm{H}, \mathrm{D}_{2} \mathrm{O}$ exchangeable, $\left.2 \times \mathrm{OH}\right), 5.73$ (brs, $1 \mathrm{H}, \mathrm{D}_{2} \mathrm{O}$ exchangeable, $\left.\mathrm{OH}\right), 5.77(\mathrm{~d}, 1 \mathrm{H}$, $\left.\mathrm{H}-1^{\prime}, J_{1^{\prime}, 2^{\prime}}=7.7 \mathrm{~Hz}\right), 7.61\left(\mathrm{t}, 1 \mathrm{H}, \mathrm{D}_{2} \mathrm{O}\right.$ exchangeable, NH, $\left.J=5.3 \mathrm{~Hz}\right), 8.04(\mathrm{~s}, 1 \mathrm{H}, \mathrm{H}-7) .{ }^{13} \mathrm{C}-\mathrm{NMR}(151$ $\left.\mathrm{MHz}, \mathrm{DMSO}-d_{6}\right) \delta 14.55\left(\mathrm{CH}_{3}\right), 37.52\left(\mathrm{CH}_{2}\right), 61.09\left(\mathrm{C}-5^{\prime}\right), 70.26\left(\mathrm{C}-3^{\prime}\right), 71.49\left(\mathrm{C}-2^{\prime}\right), 86.00\left(\mathrm{C}-4^{\prime}\right), 87.55$ (C-1'), 117.00 (C-6), 118.13 (C-7), 126.68 (C-7a), 138.26 (C-5), 154.74 (C-3a), 157.22 (C-2). HR-MS (ESI) $m / z$ : Calcd for $\mathrm{C}_{13} \mathrm{H}_{17} \mathrm{Cl}_{2} \mathrm{~N}_{4} \mathrm{O}_{4}$ : $[\mathrm{M}+\mathrm{H}]^{+}=363.0621$, found 363.0630.

5,6-Dichloro- $N$-isopropyl-1-( $\beta$-D-ribofuranosyl)- $1 H$-imidazo[4,5-b]pyridin-2-amine (13b):This compound was prepared by a procedure analogous to that described for 12a starting from 10b (90 $\mathrm{mg}, 0.18 \mathrm{mmol})$. Purification was effected by column chromatography, using a mixture of DCM/MeOH: $97 / 3$ to $88 / 12(v / v)$ as the eluent, to afford $\mathbf{1 3 b}$ (65 mg, $96 \%$ yield). White solid, mp: $191-192{ }^{\circ} \mathrm{C}$ (EtOAc/n-pentane). $[\alpha]_{\mathrm{D}}+45.80(c=0.559, \mathrm{MeOH}) .{ }^{1} \mathrm{H}$ NMR $\left(600 \mathrm{MHz}\right.$, DMSO- $\left.d_{6}\right) \delta 1.22$ $\left(\mathrm{d}, 6 \mathrm{H}, 2 \times \mathrm{CH}_{3}, J=6.6 \mathrm{~Hz}\right), 3.65\left(\mathrm{ddd}, 1 \mathrm{H}, \mathrm{H}-5^{\prime}, J_{5^{\prime}, 4^{\prime}}=2.5 \mathrm{~Hz}, J_{5^{\prime}, \mathrm{OH}}=4.4 \mathrm{~Hz}, J_{5^{\prime}, 5^{\prime}}=11.9 \mathrm{~Hz}\right), 3.71$ $\left(\mathrm{m}, 1 \mathrm{H}, \mathrm{H}-5^{\prime}\right), 4.00\left(\mathrm{~m}, 1 \mathrm{H}, \mathrm{H}-4^{\prime}\right), 4.08\left(\mathrm{~m}, 1 \mathrm{H}, \mathrm{H}-3^{\prime}\right), 4.11(\mathrm{~m}, 1 \mathrm{H}, \mathrm{CH}), 4.27\left(\mathrm{~m}, 1 \mathrm{H}, \mathrm{H}-2^{\prime}\right), 5.27(\mathrm{~d}, 1 \mathrm{H}$, $\mathrm{D}_{2} \mathrm{O}$ exchangeable, $\left.\mathrm{OH}-3^{\prime}, J=3.9 \mathrm{~Hz}\right), 5.30\left(\mathrm{~d}, 1 \mathrm{H}, \mathrm{D}_{2} \mathrm{O}\right.$ exchangeable, $\left.\mathrm{OH}-2^{\prime}, J=7.6 \mathrm{~Hz}\right), 5.70(\mathrm{t}, 1 \mathrm{H}$, $\mathrm{D}_{2} \mathrm{O}$ exchangeable, $\left.\mathrm{OH}-5^{\prime}, J=4.4 \mathrm{~Hz}\right), 5.78\left(\mathrm{~d}, 1 \mathrm{H}, \mathrm{H}-1^{\prime}, J_{1^{\prime}, 2^{\prime}}=7.8 \mathrm{~Hz}\right), 7.37\left(\mathrm{~d}, 1 \mathrm{H}, \mathrm{D}_{2} \mathrm{O}\right.$ exchangeable, $\mathrm{NH}, J=7.7 \mathrm{~Hz}), 8.02(\mathrm{~s}, 1 \mathrm{H}, \mathrm{H}-7) .{ }^{13} \mathrm{C}-\mathrm{NMR}\left(151 \mathrm{MHz}, \mathrm{DMSO}-d_{6}\right) \delta 22.23\left(\mathrm{CH}_{3}\right), 22.33\left(\mathrm{CH}_{3}\right), 44.87$ $(\mathrm{CH}), 61.11\left(\mathrm{C}-5^{\prime}\right), 70.26\left(\mathrm{C}-3^{\prime}\right), 71.49\left(\mathrm{C}-2^{\prime}\right), 86.02\left(\mathrm{C}-4^{\prime}\right), 87.53\left(\mathrm{C}-1^{\prime}\right), 116.90(\mathrm{C}-6), 117.96(\mathrm{C}-7), 126.73$ (C-7a), 138.22 (C-5), 154.76 (C-3a), 156.63 (C-2). HR-MS (ESI) m/z: Calcd for $\mathrm{C}_{14} \mathrm{H}_{19} \mathrm{Cl}_{2} \mathrm{~N}_{4} \mathrm{O}_{4}$ : $[\mathrm{M}+$ $\mathrm{H}]^{+}=377.0778$, found 377.0785 . 
$N$-Benzyl-5,6-dichloro-1-( $\beta$-D-ribofuranosyl)-1H-imidazo[4,5-b]pyridin-2-amine (13c): This compound was prepared by a procedure analogous to that described for 12a starting from 10c (60 mg, $0.11 \mathrm{mmol}$ ). Purification was effected by column chromatography, using a mixture of DCM/MeOH: $97.5 / 2.5$ to $85 / 15(v / v)$ as the eluent to afford $13 \mathrm{c}(40 \mathrm{mg}, 90 \%$ yield). White solid, mp: $136-137^{\circ} \mathrm{C}$ (toluene). $[\alpha]_{\mathrm{D}}+17.37(c=0.570, \mathrm{MeOH}) .{ }^{1} \mathrm{H}$ NMR $\left(600 \mathrm{MHz}, \mathrm{DMSO}-d_{6}\right) \delta 3.66(\mathrm{dd}, 1 \mathrm{H}$, $\left.\mathrm{H}-5^{\prime}, J_{5^{\prime}, 4^{\prime}}=2.5 \mathrm{~Hz}, J_{5^{\prime}, 5^{\prime}}=11.9 \mathrm{~Hz}\right), 3.72\left(\mathrm{dd}, 1 \mathrm{H}, \mathrm{H}-5^{\prime}, J_{5^{\prime}}, 4^{\prime}=1.8 \mathrm{~Hz}, J_{5^{\prime}, 5^{\prime}}=11.9 \mathrm{~Hz}\right), 4.03(\mathrm{~m}, 1 \mathrm{H}$, $\left.\mathrm{H}-4^{\prime}\right), 4.09\left(\mathrm{dd}, 1 \mathrm{H}, \mathrm{H}-3^{\prime}, J_{3^{\prime}, 4^{\prime}}=1.6 \mathrm{~Hz}, J_{3^{\prime}, 2^{\prime}}=5.4 \mathrm{~Hz}\right), 4.32\left(\mathrm{dd}, 1 \mathrm{H}, \mathrm{H}-2^{\prime}, J_{2^{\prime}, 3^{\prime}}=5.5 \mathrm{~Hz}, J_{2^{\prime}, 1^{\prime}}=7.8 \mathrm{~Hz}\right)$, $4.59\left(\mathrm{~d}, 2 \mathrm{H}, \mathrm{CH}_{2}, J_{\mathrm{CH} 2, \mathrm{NH}}=6.1 \mathrm{~Hz}\right), 5.07-5.57\left(\mathrm{br} \mathrm{s}, 2 \mathrm{H}, \mathrm{D}_{2} \mathrm{O}\right.$ exchangeable, $\left.2 \times \mathrm{OH}\right), 5.77(\mathrm{br} \mathrm{s}, 1 \mathrm{H}$, $\mathrm{D}_{2} \mathrm{O}$ exchangeable, $\left.\mathrm{OH}\right), 5.83\left(\mathrm{~d}, 1 \mathrm{H}, \mathrm{H}-1^{\prime}, J_{1^{\prime}, 2^{\prime}}=7.8 \mathrm{~Hz}\right), 7.24\left(\mathrm{t}, 1 \mathrm{H}\right.$, phenyl H-4 $\left.{ }^{\prime \prime}, J=7.2 \mathrm{~Hz}\right), 7.32(\mathrm{t}$,

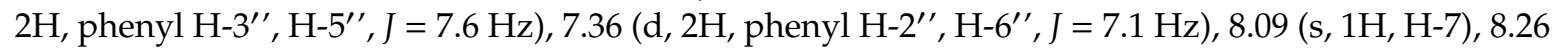
$\left(\mathrm{t}, 1 \mathrm{H}, \mathrm{D}_{2} \mathrm{O}\right.$ exchangeable, $\left.\mathrm{NH}, \mathrm{J}_{\mathrm{NH}, \mathrm{CH} 2}=6.1 \mathrm{~Hz}\right) .{ }^{13} \mathrm{C}-\mathrm{NMR}\left(151 \mathrm{MHz}, \mathrm{DMSO}-d_{6}\right) \delta 45.71\left(\mathrm{CH}_{2}\right), 61.11$ (C-5'), 70.26 (C-3'), 71.67 (C-2'), 86.10 (C-4'), 87.55 (C-1'), 117.22 (C-6), 118.50 (C-7), 126.64 (C-7a), 126.87 (phenyl C-4'), 127.21 (phenyl C-2"', C-6"'), 128.26 (phenyl C-3"', C-5'), 138.40 (C-5), 139.24 (phenyl C-1"'), 154.43 (C-3a), 157.31 (C-2). HR-MS (ESI) m/z: Calcd for $\mathrm{C}_{18} \mathrm{H}_{19} \mathrm{Cl}_{2} \mathrm{~N}_{4} \mathrm{O}_{4}$ : $[\mathrm{M}+\mathrm{H}]^{+}=425.0778$, found 425.0784 .

5,6-Dichloro-1-( $\beta$-D-ribofuranosyl)-1H-imidazo[4,5-b]pyridin-2-amine (13d): This compound was prepared by a procedure analogous to that described for 12a starting from $10 \mathrm{~d}(40 \mathrm{mg}, 0.09 \mathrm{mmol})$. Purification was effected by column chromatography, using a mixture of DCM/MeOH: 97/3 to 88/12 $(v / v)$ as the eluent, to give $13 \mathrm{~d}\left(25 \mathrm{mg}, 86 \%\right.$ yield). Beige solid, $\mathrm{mp}: 194-195{ }^{\circ} \mathrm{C}$ (toluene). $[\alpha]_{\mathrm{D}}+19.44$ $(c=0.360, \mathrm{MeOH}) .{ }^{1} \mathrm{H}$ NMR $\left(600 \mathrm{MHz}, \mathrm{DMSO}-d_{6}\right) \delta 3.64\left(\mathrm{~m}, 1 \mathrm{H}, \mathrm{H}-5^{\prime}\right), 3.70\left(\mathrm{~m}, 1 \mathrm{H}, \mathrm{H}-5^{\prime}\right), 3.99(\mathrm{~m}$, $\left.1 \mathrm{H}, \mathrm{H}-4^{\prime}\right), 4.08\left(\mathrm{dd}, 1 \mathrm{H}, \mathrm{H}-3^{\prime}, J_{3^{\prime}, 4^{\prime}}=1.5 \mathrm{~Hz}, J_{3^{\prime}, 2^{\prime}}=5.5 \mathrm{~Hz}\right), 4.29\left(\mathrm{~m}, 1 \mathrm{H}, \mathrm{H}-2^{\prime}\right), 5.25\left(\mathrm{br} \mathrm{s}, 1 \mathrm{H}, \mathrm{D}_{2} \mathrm{O}\right.$ exchangeable, $\left.\mathrm{OH}-3^{\prime}\right), 5.30$ (br s, $1 \mathrm{H}, \mathrm{D}_{2} \mathrm{O}$ exchangeable, $\mathrm{OH}-2^{\prime}$ ), 5.60 (br s, $1 \mathrm{H}, \mathrm{D}_{2} \mathrm{O}$ exchangeable, OH-5'), $5.76\left(\mathrm{~d}, 1 \mathrm{H}, \mathrm{H}-1^{\prime}, J_{1^{\prime}, 2^{\prime}}=7.7 \mathrm{~Hz}\right), 7.45\left(\mathrm{br} \mathrm{s}, 2 \mathrm{H}, \mathrm{D}_{2} \mathrm{O}\right.$ exchangeable, $\left.\mathrm{NH}_{2}\right), 8.08(\mathrm{~s}, 1 \mathrm{H}, \mathrm{H}-7)$. ${ }^{13} \mathrm{C}-\mathrm{NMR}(151 \mathrm{MHz}, \mathrm{DMSO}-d 6) \delta 61.01\left(\mathrm{C}-5^{\prime}\right), 70.07\left(\mathrm{C}-3^{\prime}\right), 71.56\left(\mathrm{C}-2^{\prime}\right), 85.96\left(\mathrm{C}-4^{\prime}\right), 87.60\left(\mathrm{C}-1^{\prime}\right), 116.70$ (C-6), 118.29 (C-7), 126.13 (C-7a), 138.41 (C-5), 154.85 (C-3a), 158.06 (C-2). HR-MS (ESI) m/z: Calcd for $\mathrm{C}_{11} \mathrm{H}_{13} \mathrm{Cl}_{2} \mathrm{~N}_{4} \mathrm{O}_{4}:[\mathrm{M}+\mathrm{H}]^{+}=335.0308$, found 335.0318.

\subsection{Antiviral Evaluation}

The compounds were evaluated against different herpesviruses, including herpes simplex virus type 1 (HSV-1) strain KOS, a thymidine kinase-deficient (TK ${ }^{-}$) HSV-1 KOS strain that is resistant to $\operatorname{ACV}\left(\mathrm{ACV}^{\mathrm{r}}\right)$, herpes simplex virus type $2(\mathrm{HSV}-2)$ strain $\mathrm{G}$, adeno virus-2, human coronavirus, varicella-zoster virus (VZV) $\mathrm{TK}^{+}$strain Oka, $\mathrm{TK}^{-}$VZV strain 07-1, and human cytomegalovirus (HCMV) strains AD-169 and Davis. The antiviral assays were based on inhibition of virus-induced cytopathicity or plaque formation (for VZV) in human embryonic lung (HEL) fibroblasts. Confluent cell cultures in microtiter 96 -well plates were inoculated with $100 \mathrm{CCID}_{50}$ of virus $\left(1 \mathrm{CCID}_{50}\right.$ being the virus dose to infect $50 \%$ of the cell cultures) or with 20 plaque forming units (PFU) (for VZV) and the cell cultures were incubated in the presence of varying concentrations of the test compounds. Viral cytopathicity or plaque formation $(\mathrm{VZV})$ was recorded as soon as it reached completion in the control virus-infected cell cultures that were not treated with the test compounds. Antiviral activity was expressed as the $\mathrm{EC}_{50}$ or compound concentration required, to reduce virus-induced cytopathicity or viral plaque formation by $50 \%$. Cytotoxicity of the test compounds was expressed as the minimum cytotoxic concentration (MCC) or the compound concentration that caused a microscopically detectable alteration of cell morphology. Alternatively, the cytostatic activity of the test compounds was measured based on inhibition of cell growth. HEL cells were seeded at a rate of $5 \times 10^{3}$ cells/well into 96-well microtiter plates and allowed to proliferate for $24 \mathrm{~h}$. Then, medium containing different concentrations of the test compounds was added. After 3 days of incubation at $37^{\circ} \mathrm{C}$, the cell number was determined with a Coulter counter. The cytostatic concentration was calculated as the CC50, or the compound concentration required to reduce cell proliferation by $50 \%$ relative to the number of cells in the untreated controls. 


\subsection{Proliferation Assay}

The human cell lines used for the proliferation were Hela (ATCC \#CCL-2, cervical carcinoma), CEM (T-lymphoblastoid cells) and HMEC-1 (human microvascular endothelialcells). First, (5-7.5) $\times$ $10^{4}$ cells were seeded onto standard 96-well microtiter plates and left to attach for $24 \mathrm{~h}$. On the next day, test compounds were added in five serial 10-fold dilutions. The cell growth rate was evaluated after $72 \mathrm{~h}$ of incubation, using MTT assay. Obtained results are expressed as an $\mathrm{IC}_{50}$ value, which stands for the concentration of the compound necessary for $50 \%$ growth inhibition. The $\mathrm{IC}_{50}$ values are calculated from concentration-response curve using linear regression analysis. Each test was performed in quadruplicate in at least two individual experiments.

Supplementary Materials: The following are available online: a figure indicating the numbering of the imidazopyridine nucleosides (Figure S1); ${ }^{1} \mathrm{H}$ - and ${ }^{13} \mathrm{C}-\mathrm{NMR}$ spectra of the target nucleosides 12a-d and 13a-d, and of the di-ribosylated by-product 14 (Figures S2-S10); the NOE spectra of target compounds 12a and 13a (Figures S11 and S12); tables with the results of the antiviral (Tables S1-S3) and the cytotoxic (Table S4) evaluation of the target nucleosides.

Author Contributions: Project conception and supervision, N.L., P.M. and N.P.; Synthesis and characterization of the compounds, G.P. and M.G.; Biological evaluation of the compounds, R.S. and G.A.; Data analysis, G.P., N.L., P.M., N.P., R.S. and G.A.; Writing of the manuscript, G.P., N.L., P.M., G.A. and N.P. All authors have read and agreed to the published version of the manuscript.

Funding: The scientific work reported in this paper was supported by the Onassis Foundation, through a postgraduate scholarship awarded to G.P. (Scholarship ID: G ZN 045-1/2017-2018).

Acknowledgments: The authors are grateful to Leentje Persoons and Brecht Dirix for excellent technical assistance in the antiviral and antiproliferative assays.

Conflicts of Interest: The authors declare no conflict of interest.

\section{References}

1. Griffiths, P.D.; Baraniak, I.; Reeves, M. The pathogenesis of human cytomegalovirus. J. Pathol. 2015, 235, 288-297. [CrossRef] [PubMed]

2. Xenaki, E.; Hassoulas, J.; Apostolakis, S.; Sourvinos, G.; Spandidos, D.A. Detection of cytomegalovirus in atherosclerotic plaques and nonatherosclerotic arteries. Angiology 2009, 60, 504-508. [CrossRef] [PubMed]

3. Li, S.; Zhu, J.; Zhang, W.; Chen, Y.; Zhang, K.; Popescu, L.M.; Ma, X.; Lau, W.B.; Rong, R.; Yu, X.; et al. Signature microRNA expression profile of essential hypertension and its novel link to human cytomegalovirus infection. Circulation 2011, 124, 175-184. [CrossRef] [PubMed]

4. Michaelis, M.; Doerr, H.W.; Cinatl, J. The story of human cytomegalovirus and cancer: Increasing evidence and open questions. Neoplasia 2009, 11, 1-9. [CrossRef]

5. Britt, W. Manifestations of human cytomegalovirus infection: Proposed mechanisms of acute and chronic disease. Curr. Top. Microbiol. Immunol. 2008, 325, 417-470.

6. Kotton, C.N.; Kumar, D.; Caliendo, A.M.; Asberg, A.; Chou, S.; Danziger-Isakov, L.; Humar, A. Transplantation society international CMV consensus group. Updated international consensus guidelines on the management of cytomegalovirus in solid-organ transplantation. Transplantation 2013, 96, 333-360. [CrossRef]

7. Choopong, P.; Vivittaworn, K.; Konlakij, D.; Thoongsuwan, S.; Pituksung, A.; Tesavibul, N. Treatment outcomes of reduced-dose intravitreal ganciclovir for cytomegalovirus retinitis. BMC Infect. Dis. 2016, 16, 164. [CrossRef]

8. Griffiths, P. New vaccines and antiviral drugs for cytomegalovirus. J. Clin. Virol. 2019, 116, 58-61. [CrossRef]

9. Göhring, K.; Hamprecht, K.; Jahn, G. Antiviral drug- and multidrug resistance in cytomegalovirus infected SCT patients. Comput. Struct. Biotechnol. J. 2015, 13, 153-158. [CrossRef]

10. Mercorelli, B.; Sinigalia, E.; Loregian, A.; Palù, G. Human cytomegalovirus DNA replication: Antiviral targets and drugs. Rev. Med. Virol. 2008, 18, 177-210. [CrossRef]

11. Marty, F.M.; Winston, D.J.; Rowley, S.D.; Vance, E.; Papanicolaou, G.A.; Mullane, K.M.; Brundage, T.M.; Robertson, A.T.; Godkin, S.; Momméja-Marin, H.; et al. CMX001 to prevent cytomegalovirus disease in hematopoietic-cell transplantation. N. Engl. J. Med. 2013, 369, 1227-1236. [CrossRef] [PubMed] 
12. Chen, H.; Li, C.; Zemlicka, J.; Gentry, B.G.; Bowlin, T.L.; Coen, D.M. Potency and stereoselectivity of cyclopropavir triphosphate action on human cytomegalovirus DNA polymerase. Antimicrob. Agents Chemother. 2016, 60, 4176-4182. [CrossRef] [PubMed]

13. Kim, E.S. Letermovir: First global approval. Drugs 2018, 78, 147-152. [CrossRef] [PubMed]

14. Prichard, M.N. Function of human cytomegalovirus UL97 kinase in viral infection and its inhibition by maribavir. Rev. Med. Virol. 2009, 19, 215-229. [CrossRef] [PubMed]

15. Marty, F.M.; Boeckh, M. Maribavir and human cytomegalovirus-what happened in the clinical trials and why might the drug have failed? Curr. Opin. Virol. 2011, 1, 555-562. [CrossRef] [PubMed]

16. Lougiakis, N.; Frakolaki, E.; Karmou, P.; Pouli, N.; Marakos, P.; Madan, V.; Bartenschlager, R.; Vassilaki, N. Novel nucleoside analogues targeting HCV replication through an NS5A-dependent inhibition mechanism. Chem. Biol. Drug Des. 2017, 90, 352-367. [CrossRef]

17. Lougiakis, N.; Marakos, P.; Pouli, N.; Fragopoulou, E.; Tenta, R. Synthesis of new nebularine analogues and their inhibitory activity against adenosine deaminase. Chem. Pharm. Bull. 2015, 63, 134-142. [CrossRef]

18. Tite, T.; Lougiakis, N.; Marakos, P.; Pouli, N. The application of mitsunobu cyclization for the synthesis of $2^{\prime}, 3^{\prime}$-dideoxy-c-nucleosides designed as didanosine analogues. Synlett 2009, 11, 1741-1744.

19. Korouli, S.; Lougiakis, N.; Marakos, P.; Pouli, N. The synthesis of the new C-nucleoside 6-deazaformycin B. Synlett 2008, 2, 181-184.

20. Biron, K.K.; Harvey, R.J.; Chamberlain, S.C.; Good, S.S.; Smith, A.A., III; Davis, M.G.; Talarico, C.L.; Miller, W.H.; Ferris, R.; Dornsife, R.E.; et al. Potent and selective inhibition of human cytomegalovirus replication by 1263 W94, a benzimidazole L-riboside with a unique mode of action. Antimicrob. Agents Chemother. 2002, 46, 2365-2372. [CrossRef]

21. Gerasi, M.; Frakolaki, E.; Papadakis, G.; Chalari, A.; Lougiakis, N.; Marakos, P.; Pouli, N.; Vassilaki, N. Design, synthesis and anti-HBV activity evaluation of new substituted imidazo[4,5-b]pyridines. Bioorg. Chem. 2020, 98, 103580. [CrossRef] [PubMed]

22. Perkins, J.J.; Zartman, A.E.; Meissner, R.S. Synthesis of 2-(Alkylamino)benzimidazoles. Tetrahedron Lett. 1999, 40, 1103-1106. [CrossRef]

23. Townsend, L.B.; Devivar, R.V.; Turk, S.R.; Nassiri, M.R.; Drach, J.C. Design, synthesis, and antiviral activity of certain 2,5,6-trihalo-1-(beta-D-ribofuranosyl)benzimidazoles. J. Med. Chem. 1995, 38, 4098-4105. [CrossRef] [PubMed]

Sample Availability: Samples of the target compounds are available from the authors.

(C) 2020 by the authors. Licensee MDPI, Basel, Switzerland. This article is an open access article distributed under the terms and conditions of the Creative Commons Attribution (CC BY) license (http://creativecommons.org/licenses/by/4.0/). 